\title{
AN EMPIRICAL ANALYSIS OF LIFE CYCLE FERTILITY AND FEMALE LABOR SUPPLY
}

\author{
By V. Joseph Hotz and Robert A. Miller ${ }^{1}$
}

\begin{abstract}
This paper examines household fertility and female labor supply over the life cycle. We investigate how maternal time inputs, market expenditures on offspring, as well as the benefits they yield their parents, vary with ages of offspring, and influence female labor supply and contraceptive behavior. Our econometric framework combines a female labor supply model and a contraceptive choice index function. It also accounts for the fact that conceptions are not perfectly controllable events. Using longitudinal data on married couples from the Panel Study of Income Dynamics, we estimate these equations and test alternative specifications of the technologies governing child care. Our findings suggest that while parents cannot perfectly control conceptions, variations in child care costs do affect the life cycle spacing of births. Furthermore, our results demonstrate the gains of modelling the linkages between female labor supply and fertility behavior at the household level.
\end{abstract}

KeYwords: Fertility, female labor supply, life cycle models, child care costs.

\section{INTRODUCTION}

THE MODERN APPROACH to population economics has emphasized the importance of variation in the value of time to explain the observed changes in fertility patterns at both the aggregate and household levels. Applying the principles of consumer demand theory, this line of research has espoused the view that family size is the result of parental choice constrained by financial and time constraints. In particular it has been argued that variation in the opportunity cost of parental time in child care helps determine the observed fertility patterns in modern industrial societies. (See Mincer (1963), Becker (1965), Willis (1973), and Butz and Ward (1979).)

Much of this research has been based on theoretical and econometric models of completed fertility demanded by parents over their lifetimes. But, as has been noted by several authors (see Namboodiri (1972) and Heckman and Willis (1976)), there are important objections to these static models of fertility. Such models ignore the durable and irreversible nature of children as consumption goods, the stochastic nature of the human reproduction process, as well as the uncertainty and variability in parental income streams and market wage rate realizations over the life cycle. These considerations highlight the inherently sequential nature of fertility decision making and suggest the potential value of focusing on the timing and spacing of births over the life cycle in analyzing household fertility behavior.

\footnotetext{
${ }^{1}$ We have benefited from the comments of Ricardo Barros, Angus Deaton, Robert Moffitt, Mark Montgomery, Thomas Mroz, James Walker, Robert Willis, and two anonymous referees as well as participants in workshops at ANU, Carnegie-Mellon, Chicago, Duke, McMaster, Monash, Penn, Princeton, SUNY-Stony Brook, University of Washington, Western Ontario, and Yale on previous drafts of this paper. We especially wish to thank Kim Balls for his able research assistance and for his comments. This research was supported by NICHD Grant R23HD16049.
} 
In this paper, we adopt a dynamic approach to analyze both fertility and the related life cycle labor supply behavior of married women. We investigate how maternal time inputs, market expenditures on offspring, as well as the benefits they yield their parents, vary with ages of offspring and influence female labor supply and contraceptive behavior. The empirical specifications adopted below enable us to investigate these linkages between fertility and other household allocation decisions over the life cycle and test various hypotheses, previously maintained in the literature, which relate to the parental provision of care to their offspring.

A consistent finding in empirical studies of female labor supply is the importance of variation in the number and age distribution of children on hours of work and labor force participation for this group. (See Mincer (1962), Cain (1966), Heckman (1974), and Schultz (1978).) In addition, the number and age composition have also been found to have significant effects on household expenditure patterns. (See Pollak and Wales (1980), Espenshade (1984), and Deaton and Muellbauer (1980).) Hill and Stafford (1980) have found that the time intensity of maternal time inputs to children markedly decline as children grow up. All these studies treat children as exogenously imposed constraints on household decision making. Our analysis departs from this latter approach by recognizing that such constraints are chosen by parents indirectly via the contraceptive strategies they follow over their lifetimes.

We use longitudinal data on households obtained from the Panel Study of Income Dynamics (PSID). In addition to information on birth histories, female labor supply, income, and wages, our analysis exploits a measure of how much time each interviewed mother spent tending her children. This latter information enables us to estimate directly the mother's child care process. The econometric framework combines a female labor supply model, similar to those developed by Heckman (1974) and Heckman and MaCurdy (1980), with an index function to explain contraceptive practice. Although information on contraceptive use is not collected by the PSID, our framework nevertheless accounts for the fact that birth control measures sometimes fail, and that conception does not necessarily occur as soon as couples stop contraception. In the empirical analysis, we contro for several sources of unobserved heterogeneity across households in the estima. tion of the female labor supply equation and the contraceptive choice indes function. Several specifications for the maternal time and money devoted to the rearing of offspring are estimated and tested. We explore the ramifications $o$ these different specifications for characterizing life cycle household fertilit: behavior.

A number of findings emerge from our investigation. First, the restriction implied by linkages (due to child care costs) on observed life cycle fertility anc time allocation patterns are not rejected. We find the intensity of child care in thi mother's time (relative to other inputs) declines as the children age. Moreover the mother's time spent in child care has a significant negative effect on th likelihood of having another birth as well as tending to reduce the mother's labo supply. Second, increases in the father's income significantly increase the prob 
ability of another birth. The latter finding is of interest given the frequently found negative association between measures of husband's income and completed family size in many previous studies. (See, for example, Willis (1973).) Third, our estimates show that while the timing of births over the life cycle is not perfectly controllable, the effects of the spacing decisions by parents, via their contraceptive practices, are detected in the data.

The paper is organized as follows. The next section lays out the empirical specifications for household contraceptive choice, female labor supply, and child care costs used in our empirical analysis and discusses strategies for estimation and hypothesis testing. Then in Section 3, we describe the sample used and present our empirical results. We present estimates, and associated test statistics, for several alternative specifications of how parental child care affects female labor supply and the timing of births and plots that illustrate the implications of these alternative specifications for the hazard function of births.

\section{AN EMPIRICAL SPECIFICATION}

In this section, we present an empirical specification of female time allocation and fertility over the life cycle which accounts for linkages between these household decisions and which can be estimated with household panel data. We limit our analysis to continuously married couples who have at least one child. ${ }^{2}$ Three components comprise the econometric framework. The first is a specification of the mother's labor supply as well as an equation characterizing her market wage rate over time. The second component models the observed sequence of births over the life cycle in terms of an index function determining parental contraceptive decisions and the probabilities of conception associated with these decisions. The third component characterizes the costs to the parents of caring for their offspring which affect both the mother's labor supply and fertility decisions.

We first consider the mother's labor supply function, the index function governing her labor force participation and the exogenous process governing her market wage rate. Consider the $i$ th household and index time periods according to the mother's age, $t_{i}$. Let $d_{i t} \in\{0,1\}$ indicate the mother's participation in the work force at age $t_{i}$. If $d_{i t}$ is zero, she specializes in nonmarket activities; if not, her hours of work are denoted by $h_{i t}$. For a mother participating in the labor force at age $t_{i}, h_{i t}$ (and the associated condition governing her labor force participation decision) is assumed to be a linear function of her husband's income, $y_{i t}$, her market wage rate, $w_{i t}$, her time costs in rearing existing children,

\footnotetext{
${ }^{2}$ Since we are primarily interested in marital fertility, we have not modelled marital formation and dissolution. Restricting the sample to continuously married couples may induce a form of selection bias in our empirical analysis. To the extent family formation and dissolution decisions are correlated with childbearing decisions, via time-varying factors not observed by the econometrician, our estimates may not yield valid behavioral inferences about fertility or female labor supply. Because our focus is primarily on the influence of child care costs on the timing of births and female labor supply, we only model the timing of birth parities higher than the first. Thus, caution must be exercised in projecting our results beyond households with intact marriages which bear at least some children.
} 
$c_{i t}$, expenditures on market goods for her children, $a_{i t}$, and a disturbance term, $u_{1 i t}$. Thus the labor supply specification is given by

$$
\begin{aligned}
d_{i t} & =\left\{\begin{array}{lll}
1 & \text { when } & \eta_{1} y_{i t}+\eta_{2} w_{i t}+\eta_{3} c_{i t}+\eta_{4} a_{i t} \geqslant-u_{1 i t}, \\
0 & \text { when } & \eta_{1} y_{i t}+\eta_{2} w_{i t}+\eta_{3} c_{i t}+\eta_{4} a_{i t}<-u_{1 i t},
\end{array}\right. \\
h_{i t} & =d_{i t}\left(\eta_{1} y_{i t}+\eta_{2} w_{i t}+\eta_{3} c_{i t}+\eta_{4} a_{i t}+u_{1 i t}\right) .
\end{aligned}
$$

We assume the process generating husband's income is exogenous. The process governing the mother's market wage rate is assumed to be a linear function of her age, age squared, and a stochastic component, $u_{2 i t}$. That is,

$$
w_{i t}=\alpha_{1} t_{i}+\alpha_{2} t_{i}^{2}+u_{2 i t} \text {. }
$$

The above formulation of female labor supply and the female market wage process closely resembles previous formulations found in the literature (such as Heckman (1974)). However, we explicitly model the influence of child care costs on the female's labor supply decisions. The inclusion of child care costs in our labor supply specification is motivated by empirical findings that the number and age distribution significantly affect married women's labor supply behavior. To characterize the relationship between the number (and ages) of offspring and such costs, consider the following representation of maternal time and market goods devoted to the care of existing children. Let $b_{i t}$ measure birth events for the $i$ th household when the mother is $t_{i}$ years old, where $b_{i t}=1$ when a birth occurs and is zero otherwise. With respect to market goods used in the care of children, suppose a $k$ year old child requires expenditures of $\psi_{k}$. Then $a_{i t}$ is given by

$$
a_{i t}=\sum_{k=1}^{t} \psi_{k} b_{i, t-k}
$$

Similarly, assume that children of age $k$ receive $\gamma_{k}$ units of the mother's time inputs. ${ }^{3}$ Then $c_{i t}$ is given by

$$
c_{i t}=\sum_{k=1}^{t} \gamma_{k} b_{i, t-k} \text {. }
$$

Equations (2.4) and (2.5) nest several specializations of child care costs (or the associated child care technology) considered in the literature. With respect to market input expenditures, some studies of the cost of children, such as Espenshade (1984), find that $\psi_{k}$ rises as children age; other studies, such as Gronau (1986), cannot reject the hypothesis that such costs do not vary with age, that is, $\psi_{k}=\psi_{1}$ for all $k$. As noted above, Hill and Stafford (1980) find, using data from time diaries, that maternal time devoted to child care declines as the children age. To capture this latter pattern, suppose that the demands a child makes on its mother's time declines geometrically with its age, so that $\gamma_{k}=\gamma_{1} \delta^{k-1}$ for all $k$, where $0<\delta<1$. Then the mother's total child care time commitment

\footnotetext{
${ }^{3} \mathrm{We}$ assume that the father spends no time in the rearing of his offspring.
} 
when the mother is age $t_{i}$ is

$$
c_{i t}=\sum_{k=1}^{t} \gamma_{1} \delta^{k-1} b_{i, t-k} .
$$

In the empirical analysis below we examine the validity of these alternatives via their influences on the mother's labor supply behavior and the household's contraceptive choices. ${ }^{4}$

To account for the possibility that the disturbances in (2.2) and (2.3) contain both persistent and transitory components, we assume that the distribution of $\left(u_{1 i t}, u_{2 i t}\right)$ is characterized by an error components structure. We assume that $u_{1 i t}$ and $u_{2 i t}$ can be written as ${ }^{5}$

$$
\begin{aligned}
& u_{1 i t}=\kappa_{1 i}+u_{1 i t}^{*}, \\
& u_{2 i t}=\kappa_{2 i}+u_{2 i t}^{*},
\end{aligned}
$$

where $\kappa_{1 i}$ and $\kappa_{2 i}$ are household specific permanent components and $u_{1 i t}^{*}$ and $u_{2 i t}^{*}$ are independently and identically distributed (across both $i$ and $t$ ) transitory components having zero means and covariance matrix, $\Sigma$, with elements $\sigma_{11}, \sigma_{22}$, and $\sigma_{12}$. The former components can be viewed as reflecting permanent unobserved differences across women in tastes for market work versus homemaking and/or productivity in the two sectors. In our empirical analysis, $\left(u_{1 i t}^{*}, u_{2 i t}^{*}\right)$ is assumed to have a bivariate normal distribution. Following Heckman and MaCurdy (1980), the vector ${\underset{\sim}{\alpha}}_{i} \equiv\left(\kappa_{1 i}, \kappa_{2 i}\right)^{\prime}$ is treated as a fixed household-specific set of parameters to be estimated. The advantages and disadvantages of treating these latter components as fixed effects are discussed below.

The third component of our econometric specification characterizes fertility behavior. Consistent with mathematical models of human reproduction (such as Sheps and Menken (1973)), we assume that birth outcomes are stochastically controlled by contraceptive measures taken by parents. In each period, parents make contraceptive choices based on their current assessment of the net benefits of having an additional child. We assume their assessments depend upon the husband's current income, the factors (both observed and unobserved) governing the wife's future wage prospects, her tastes for work, and the costs of rearing existing offspring. In addition to these factors, parental desires for having a birth when the mother is $t_{i}$ years old also depend upon the utility or services derived from existing children. Hence the couples' contraceptive decisions will depend

\footnotetext{
${ }^{4}$ Our specifications for child care costs ignore two issues which have been examined in the literature. First, they imply that the child care process exhibits constant returns to scale in the number of existing children. The evidence on the importance of such scale economies is mixed; Lazear and Michael (1980) find evidence of large scale economies while Espenshade (1984) finds them to be small. (An additional child results in reduction of the marginal expenditures of only around 5 per cent.) Second, by assuming that the coefficients in (2.4) and (2.5) are fixed weights, no substitution is allowed between market and maternal time inputs in the care of children. Below we report test results for this latter source of misspecification.

${ }^{5}$ Clearly, the specification in (2.7) does not capture all forms of intertemporal persistence in the typical household's disturbances. For example, it does not account for an autoregressive structure on $\left(u_{1 i t}, u_{2 i t}\right)$.
} 
upon their childbearing history. Given a particular choice, births occur stochastically at each age, with the probability of occurrence depending upon that choice.

More precisely, we assume that parents' contraceptive decisions are characterized by an index function, $\boldsymbol{\nu}_{i t}$, of the following form:

$$
\begin{aligned}
\nu_{i t}= & \nu_{0}+\nu_{1} y_{i t}+\nu_{2} c_{i t}+\nu_{3} a_{i t} \\
& +\sum_{k=1}^{t} \nu_{4 k} b_{i, t-k}+\nu_{5} t_{i}+\sum_{j=1}^{2}\left(\nu_{5+j} \kappa_{j i}+\nu_{7+j} u_{j i t}^{*}\right) .
\end{aligned}
$$

The mother's age, $t_{i}$, is included in (2.8) to account for the fact that women at different ages have different market wage prospects given the age trend in their market wage opportunities. The influence of the mother's age on contraceptive decisions may also reflect the fact that parental desires for children differ depending upon the amount of time left before the wife reaches menopause and is no longer fertile. ${ }^{6}$ The influence of the parent's current birth history on $\nu_{i t}$ is captured by separately including lagged births in (2.8). Previous studies of the timing of births (such as Wolpin (1984) or Hotz (1980)) have assumed that the utility or services parents receive from existing children are age-invariant, i.e., they only depend upon the number of existing children. This amounts to assuming that $\nu_{4 k}=\nu_{41}$, for all $k$. Our empirical analysis examines the validity of this assumption.

Let $p_{i t}$ denote the probability a birth occurs to the $i$ th household when its mother is $t_{i}$ years old. Those parents who desire a birth, when the mother is $t_{i}$ years old, will attempt to conceive (i.e., will choose not to contracept); they will be successful with probability $\bar{p}$. Those who wish to avoid a birth, when the mother is $t_{i}$ years old, will choose to contracept, but with probability $p$ an unwanted birth occurs nevertheless. Given the value of $\nu_{i t}$, the probability of conception is governed by the following rule:

$$
p_{i t}=\left\{\begin{array}{lll}
\bar{p} & \text { when } & \nu_{i t} \geqslant 0, \\
\underline{p} & \text { when } & \nu_{i t}<0 .
\end{array}\right.
$$

An interpretation of the above equations can be motivated by a more explicit model of parental choice over the life cycle. ${ }^{7}$ Suppose parents derive pleasure from their offspring and the consumption of a composite commodity. The commodity is produced from time spent in homemaking and inputs purchased with the household's income. Offspring are also nurtured with parental time and traded inputs, and yield service flows to the household, all of which are age dependent. Reproduction is stochastic, albeit controlled to some extent by contraceptive measures taken by the parents. Real wages facing the parents are modelled as exogenous stochastic processes, and furthermore the father specializes in market activities. Each period the parents choose a level of contraception, and the mother's time is allocated between child care, homemaking, and labor

\footnotetext{
${ }^{6}$ See David and Mroz (1986) for a model of the timing and spacing of births in which the amount of time remaining in a couple's reproductive career is shown to differentially affect their probability of conception.

${ }^{7}$ This model is developed in Hotz and Miller (1986).
} 
market activities. Their decisions sequentially maximize the expected value of an intertemporally additively separable utility function, subject to the constraint that expenditure does not exceed joint market income in any period. The specifications in (2.1), (2.2), (2.8), and (2.9) are linear approximations to the optimal decision rule for this problem.

We now consider strategies for estimating the identifiable parameters in this model. As described in the next section, our sample consists of households headed by married couples for which we observe a segment of their life cycles. Let $t_{i}$ be the $i$ th mother's age when the household enters the sample and let $\bar{t}_{i}$ denote her age at the end of the segment. At each age from $\underline{t}_{i}$ to $\bar{t}_{i}$, we observe the following: whether the mother participated in the labor force and, if she worked, her hours of work and market wage rate; the husband's income; whether the household had a birth; and the number and ages of children born to the parents as of $t_{i}$. We also have, in one year of the panel, a measure of the mother's time devoted to child care. Unfortunately, we do not have direct observations on the contraceptive actions parents took or any good measures of expenditures on child care. We establish below what parameters can be identified, and thus estimated, with this data.

Substituting the right-hand sides of (2.4), (2.5), and (2.7) for $a_{i t}, c_{i t}$, and $\left(u_{1 i t}, u_{2 i t}\right)$, respectively, equations $(2.1),(2.2),(2.3)$, and (2.8) can be written as

$$
\begin{aligned}
& d_{i t}=\left\{\begin{array}{lll}
1 & \text { when } & \tilde{h}_{i t} \geqslant-\varepsilon_{1 i t}, \\
0 & \text { when } & \tilde{h}_{i t}<-\varepsilon_{1 i t}
\end{array}\right. \\
& h_{i t}=d_{i t}\left(\tilde{h}_{i t}+\varepsilon_{1 i t}\right) \text {, } \\
& w_{i t}=\tilde{w}_{i t}+\varepsilon_{2 i t} \text {, } \\
& \nu_{i t}=\tilde{\nu}_{i t} \sqrt{\omega_{33}}+\varepsilon_{3 i t} \text {, }
\end{aligned}
$$

where

$$
\begin{aligned}
& \tilde{h}_{i t} \equiv \eta_{1} y_{i t}+\eta_{2}\left(\alpha_{0}+\alpha_{1} t_{i}+\alpha_{2} t_{i}^{2}+\kappa_{2 i}\right)+\sum_{k=1}^{K}\left(\eta_{3} \gamma_{k}+\eta_{4} \psi_{k}\right) b_{i, t-k}+\kappa_{1 i}, \\
& \tilde{w}_{i t} \equiv \alpha_{1} t_{i}+\alpha_{2} t_{i}^{2}+\kappa_{2 i}, \\
& \tilde{\nu}_{i t}=\tilde{\nu}_{0}+\tilde{\nu}_{1} y_{i t}+\sum_{k=1}^{K}\left(\tilde{\nu}_{2} \gamma_{k}+\tilde{\nu}_{3} \psi_{k}+\tilde{\nu}_{4 k}\right) b_{i, t-k}+\tilde{\nu}_{5} t_{i}+\tilde{\nu}_{6} \kappa_{1 i}+\tilde{\nu}_{7} \kappa_{2 i},
\end{aligned}
$$

and $\tilde{\nu}_{j} \sqrt{\omega_{33}}=\nu_{j}$, for $j=0, \ldots, 9$. The maximum number of lagged births included in the mother's labor supply and the household's contraceptive index functions is $K$, the age of the oldest child observed in the sample. The disturbances, $\varepsilon_{1 i t}, \varepsilon_{2 i t}$, and $\varepsilon_{3 i t}$, in (2.10) are normally distributed and defined as

$$
\begin{aligned}
\varepsilon_{1 i t} & =u_{1 i t}^{*}+\eta_{2} u_{2 i t}^{*}, \\
\varepsilon_{2 i t} & =u_{2 i t}^{*}, \\
\varepsilon_{3 i t} & =\tilde{\nu}_{8} u_{1 i t}^{*}+\tilde{\nu}_{9} u_{2 i t}^{*},
\end{aligned}
$$


with covariance matrix, $\Omega$, in which the elements are

$$
\begin{aligned}
& \omega_{11}=\sigma_{11}+2 \eta_{2} \sigma_{12}+\eta_{2}^{2} \sigma_{22}, \\
& \omega_{22}=\sigma_{22}, \\
& \omega_{33}=\tilde{\nu}_{8}^{2} \sigma_{11}+2 \tilde{\nu}_{8} \tilde{\nu}_{9} \sigma_{12}+\tilde{\nu}_{9}^{2} \sigma_{22}, \\
& \omega_{12}=\sigma_{12}+\eta_{2} \sigma_{22}, \\
& \omega_{13}=\tilde{\nu}_{8} \sigma_{11}+\left(\tilde{\nu}_{9}+\eta_{2} \tilde{\nu}_{8}\right) \sigma_{12}+\eta_{2} \tilde{\nu}_{9} \sigma_{22}, \\
& \omega_{23}=\tilde{\nu}_{8} \sigma_{12}+\tilde{\nu}_{9} \sigma_{22} .
\end{aligned}
$$

Given realizations for the husband's life cycle income sequence, the stochastic process for $\left(u_{1 i t}, u_{2 i t}\right)$ and the conception probabilities, $(p, \bar{p})$, generate, via the laws of motion in (2.4) and (2.5), a probability distribution for the $i$ th household's life cycle sequence of births, the mother's market wage rates, and her labor supply. Because of the error components specification of $\left(u_{1 i t}, u_{2 i t}\right)$ given in (2.7), in which $\left(u_{1 i t}^{*}, u_{2 i t}^{*}\right)$ is serially uncorrelated and $\boldsymbol{\kappa}_{i}$ are treated as parameters, the $i$ th household's contribution to the conditional likelihood function for the sequence of outcomes over the interval $\left(\underline{t}_{i}, \bar{t}_{i}\right)$, given its birth history as of $\underline{t}_{i}$, husband's income, and $\underset{\sim}{i}$, takes the form

$$
\prod_{t=t_{i}}^{\bar{t}_{i}} \operatorname{Pr}\left(b_{i t}, h_{i t}, w_{i t} \mid\left\{b_{i, t-k}\right\}_{k=1}^{K}, y_{i t}, \kappa_{i}\right) \text {. }
$$

Treating $\kappa_{i}$ as a vector of fixed effects has several advantages over a random effect specification. The latter approach requires one to specify a parametric distribution for $\kappa_{i}$. To use a random effects specification, one must estimate the marginal probability distribution of the birth sequence prior to $\underline{t}_{i}$, since ${\underset{\sim}{\boldsymbol{\kappa}}}_{i}$ and $b_{i t}$ are not independent. One also would have to parameterize the probability density function governing the father's income process in order to characterize his income in the pre-sample period. The fixed effects approach avoids the difficulties associated with this initial conditions problem as well as the need to make further distributional assumptions.

In principle one could exploit (2.14) to form the full information maximum likelihood (FIML) estimator; in practice, this is computationally burdensome. To see this, consider the probability that at age $t_{i}$, the $i$ th mother does not participate in the labor force and a birth occurs. Since we do not observe whether the birth was desired or accidental, both possibilities must be properly accounted for in the probability. That is

$$
\begin{aligned}
\operatorname{Pr}\left(b_{i t}=\right. & \left.1, d_{i t}=0 \mid\left\{b_{i, t-k}\right\}_{k=1}^{K}, y_{i t},{ }_{\sim}{ }_{i}\right) \\
= & \operatorname{Pr}\left(b_{i t}=1 \mid d_{i t}=0, \nu_{i t} \geqslant 0\right) \\
& \times \operatorname{Pr}\left(d_{i t}=0, \nu_{i t} \geqslant 0 \mid\left\{b_{i, t-k}\right\}_{k=1}^{K}, y_{i t},{\underset{\sim}{\kappa} i}_{i}\right) \\
& +\operatorname{Pr}\left(b_{i t}=1 \mid d_{i t}=0, \nu_{i t}<0\right) \\
& \times \operatorname{Pr}\left(d_{i t}=0, \nu_{i t}<0 \mid\left\{b_{i, t-k}\right\}_{k=1}^{K}, y_{i t},{\underset{\sim}{\kappa}}_{i}\right) \\
= & \bar{p} \Phi_{2}\left(-\tilde{h}_{i t} / \sqrt{\omega_{11}}, \tilde{\nu}_{i t} ;-\omega_{13} / \sqrt{\omega_{11} \omega_{33}}\right) \\
& +\underline{p}_{2}\left(-\tilde{h}_{i t} / \sqrt{\omega_{11}},-\tilde{\nu}_{i t} ; \omega_{13} / \sqrt{\omega_{11} \omega_{33}}\right),
\end{aligned}
$$


where $\Phi_{2}\left(\varepsilon_{1}, \varepsilon_{2} ; \rho\right)$ is the bivariate standard normal distribution function for the random variables $\left(\varepsilon_{1}, \varepsilon_{2}\right)$ with correlation coefficient $\rho$. Repeated calculation of such bivariate distribution functions is computationally expensive. In addition, observe that the log-likelihood function for the FIML estimator requires one to compute, for each observation, the log of the expression in (2.15), consisting of linear combinations of bivariate distribution functions involving almost all the model's parameters.

To avoid this computational burden, at some loss of asymptotic efficiency, we use an alternative estimation strategy. In particular, we form generalized methods of moments (GMM) estimators using the score functions for likelihood functions associated with each of three separate components of the model. The three components characterize, respectively, the specification of: (i) the mother's time inputs into child care given by (2.5), using the measure of this input in our data; (ii) the female market wage process and labor supply behavior; and (iii) the household's fertility outcomes. GMM estimators formed in this way only require calculation of univariate normal distribution functions; moreover, the estimators formed by estimating each component separately are just limited information ML (or quasi-ML) estimators.

Consider first the estimation of (2.5). Let $\tilde{c}_{i \tau}$ denote the error-ridden measure in the data set of the time spent in child care by the $i$ th mother when she is age $\tau_{i}$. That is

$$
\tilde{c}_{i \tau}=\sum_{k=1}^{K} \gamma_{k} b_{i, \tau_{i}-k}+\varepsilon_{4 i},
$$

where $\varepsilon_{4 i}$ is an independently and identically distributed measurement error with mean zero and variance $\omega_{44}$. Let $\pi_{1}$, a $(K+1)$ dimensional vector, denote the parameters appearing in this component, and $l_{1 i}\left(\pi_{1}\right)$ denote the contribution to a (quasi) log-likelihood for the $i$ th household. That is,

$$
\begin{aligned}
& {\underset{\sim}{\sim}}_{1} \equiv\left(\pi_{11}, \ldots, \pi_{1 K}, \pi_{1, K+1}\right)^{\prime} \\
& \quad=\left(\gamma_{1}, \ldots, \gamma_{K}, \omega_{44}\right)^{\prime}, \\
& l_{1 i}\left(\pi_{\sim}\right)=\ln \phi\left[\omega_{44}^{-1 / 2}\left[\tilde{c}_{i \tau}-\sum_{k=1}^{K} \gamma_{k} b_{i, \tau_{i}-k}\right]\right],
\end{aligned}
$$

where $\phi()$ denotes the univariate standard normal density function. Quasi-ML estimates of ${\underset{\pi}{1}}_{1}$ are found by optimizing the sum of $l_{1 i}\left(\pi_{1}\right)$ over $i \in\{1, \ldots, N\}{ }^{8}$

The second component is based on the probability of the joint distribution for the mother's labor supply and her wage rate at age $t_{i}$ which, conditional on past births, husband's income, and household specific effects, derives from the distri-

\footnotetext{
${ }^{8}$ White (1982), among others, has shown that the consistency and asymptotic normality of such estimators does not require that the disturbances be normally distributed.
} 
bution of the unobserved disturbances, $\left(\varepsilon_{1 i t}, \varepsilon_{2 i t}\right)$. That is,

$$
\operatorname{Pr}\left(h_{i t}, w_{i t} \mid\left\{b_{i, t-k}\right\}_{k=1}^{K}, y_{i t}, \kappa_{i}\right) \text {. }
$$

The $(K+7)$ dimensional vector of parameters identified in this component, $\pi_{2}$, and the associated contribution to the log-likelihood function, $l_{2 i}\left(\pi_{2}, \boldsymbol{\kappa}_{i}\right)$, are given by

$$
\begin{aligned}
& \underset{\sim}{\pi_{2}} \equiv\left(\pi_{21}, \ldots, \pi_{2, K+7}\right)^{\prime} \\
& =\left(\eta_{1}, \eta_{2}, \alpha_{1}, \alpha_{2},\left(\eta_{3} \gamma_{1}+\eta_{4} \psi_{1}\right), \ldots,\left(\eta_{3} \gamma_{K}+\eta_{4} \psi_{K}\right), \omega_{11}, \omega_{12}, \omega_{22}\right)^{\prime}, \\
& l_{2 i}\left({\underset{\sim}{2}}_{2}, \underset{\sim}{\kappa_{i}}\right)=\sum_{t=\underline{t}_{i}}^{\bar{t}_{i}}\left\{\left(1-d_{i t}\right) \ln \Phi\left[\frac{\tilde{h}_{i t}}{\sqrt{\omega_{11}}}\right]+d_{i t}\right\} \ln \phi\left[\frac{h_{i t}-\tilde{h}_{i t}}{\sqrt{\omega_{11}}}\right] \\
& \left.+\ln \phi\left[\frac{w_{i t}-\tilde{w}_{i t}-\frac{\omega_{12}}{\omega_{11}}\left(h_{i t}-\tilde{h}_{i t}\right)}{\left[\omega_{22}-\frac{\left(\omega_{12}\right)^{2}}{\omega_{11}}\right]^{1 / 2}}\right]\right\},
\end{aligned}
$$

where $\Phi()$ is the distribution function for the standard normal distribution. To obtain ML estimates for $\underset{\sim}{\boldsymbol{\kappa}}$ and $\pi_{2}$, the sum of $l_{2 i}\left(\pi_{2},{ }_{\sim}\right)$ over $i \in\{1, \ldots, N\}$ is maximized with respect to ${\underset{\sim}{2}}_{2}$ and $\tilde{\sim}_{i}$ for each $i$.

The third component is derived from the probability of observing the $i$ th household's birth sequence over the sample period, conditional on the father's income stream, previous births, and the fixed effects, ${\underset{\sim}{i}}_{i}$. That is

$$
\begin{aligned}
\prod_{t=\underline{t}_{i}}^{\bar{t}_{i}} \operatorname{Pr} & \left(b_{i t} \mid\left\{b_{i, t-k}\right\}_{k=1}^{K}, y_{i t},{\underset{\sim}{i}}_{i}\right) \\
= & \prod_{t=\underline{t}_{i}}^{\bar{t}_{i}} b_{i t}\left[\underline{p}+(\bar{p}-\underline{p}) \operatorname{Pr}\left(\nu_{i t}>0 \mid\left\{b_{i, t-k}\right\}_{k=1}^{K}, y_{i t},,_{i}\right)\right] \\
& +\left(1-b_{i t}\right)\left[1-\underline{p}-(\bar{p}-\underline{p}) \operatorname{Pr}\left(\nu_{i t}>0 \mid\left\{b_{i, t-k}\right\}_{k=1}^{K}, y_{i t}, \underset{\sim}{,}\right)\right] \\
= & \prod_{t=\underline{t}_{i}}^{\bar{t}_{i}}\left\{\left(1-b_{i t}\right)+\left(2 b_{i t}-1\right)\left[\underline{p}+(\bar{p}-\underline{p}) \Phi\left(\tilde{\nu}_{i t}\right)\right]\right\} .
\end{aligned}
$$

The parameters for this component, a $(K+7)$ dimensional vector denoted ${\underset{\sim}{3}}_{3}$, and the contribution to the log-likelihood by the $i$ th household, $l_{3 i}\left(\underset{\sim}{\pi_{3}}, \underset{\sim}{\kappa}\right)$, are 
defined respectively as

$$
\begin{aligned}
\pi_{3} & \equiv\left(\pi_{31}, \ldots, \pi_{3, K+7}\right)^{\prime} \\
& =\left(\underline{p}, \bar{p}, \tilde{\nu}_{0}, \tilde{\nu}_{1},\left(\tilde{\nu}_{2} \gamma_{1}+\tilde{\nu}_{3} \psi_{1}+\tilde{\nu}_{41}\right), \ldots,\left(\tilde{\nu}_{2} \gamma_{K}+\tilde{\nu}_{3} \psi_{K}+\tilde{\nu}_{4 K}\right), \tilde{\nu}_{5}, \tilde{\nu}_{6}, \tilde{\nu}_{7}\right)^{\prime}, \\
& l_{3 i}\left({\underset{\pi}{3}}_{3}, \sim_{\sim}\right)=\sum_{t=t_{i}}^{\bar{t}_{i}} \ln \left\{\left(1-b_{i t}\right)+\left(2 b_{i t}-1\right)\left[\underline{p}+(\bar{p}-\underline{p}) \Phi\left(\tilde{\nu}_{i t}\right)\right]\right\} .
\end{aligned}
$$

ML estimates for the identified elements of ${\underset{\sim}{\kappa} i}_{i}$ and $\pi_{3}$ can be obtained by maximizing the sum of $l_{3 i}\left({\underset{\sim}{3}}_{3},{\underset{\sim}{i}}_{i}\right)$ over $i \in\{1, \ldots, N\}$ with respect to $\underset{\sim}{\underset{i}{*}}$ and ${\underset{\sim}{3}}_{3}$.

While one can estimate each of these three components separately to obtain ML (or quasi-ML) estimates for $\pi_{1}, \pi_{2}, \pi_{3}$, and $\left\{{\underset{\sim}{\kappa}}_{i}\right\}_{i=1}^{N}$, respectively, we are interested in imposing and testing sets of cross-equation parameter restrictions arising from the common influence of $c_{i t}$ and $a_{i t}$ on both female labor supply and the household's fertility decisions. Forming the following GMM estimators affords us the opportunity of imposing such restrictions in estimation while still avoiding the computational burdens of FIML estimation described above. Let $\pi$ denote the parameters contained in $\left(\pi_{1}^{\prime}, \pi_{2}^{\prime}, \pi_{3}^{\prime}\right)^{\prime}$. Let $m_{i}\left(\pi, \kappa_{i}\right)$ denote the derivative with respect to $\pi$ of the sum of the $i$ th household's contribution to the three log-likelihood functions just considered. That is

$$
\underline{\sim}_{i}\left(\underline{\sim}_{\sim}, \underline{\sim}_{i}\right)=\partial\left[l_{1 i}\left(\boldsymbol{\pi}_{1}\right)+l_{2 i}\left(\underline{\sim}_{2}, \kappa_{i}\right)+l_{3 i}\left(\boldsymbol{\pi}_{3}, \underline{\sim}_{i}\right)\right] / \partial \underset{\sim}{\pi} .
$$

Then given $\left\{{\underset{\sim}{\boldsymbol{\kappa}}}_{i}\right\}_{i=1}^{N}$, GMM estimators can be found by minimizing

$$
\left[\frac{1}{N} \sum_{i=1}^{N}{\underset{\sim}{m}}_{i}\left(\underset{\sim}{\pi}, \kappa_{i}\right)\right]^{\prime} W_{N}\left[\frac{1}{N} \sum_{i=1}^{N}{\underset{\sim}{i}}_{i}\left(\underset{\sim}{\pi}, \underset{\sim}{\kappa_{i}}\right)\right],
$$

with respect to $\underset{\sim}{\pi}$, where $W_{N}$ is a positive definite weighting matrix that converges to some $W$ as $N$, the sample size, increases. The estimators obtained in this manner would have a covariance matrix, $\Lambda=\left(D^{\prime} W D\right)^{-1} D^{\prime} W V W D\left(D^{\prime} W D\right)^{-1}$,

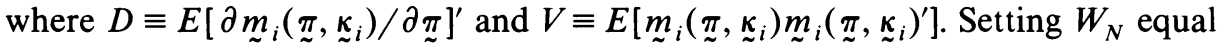
to the identity matrix corresponds to forming estimators which maximize the sum of likelihood functions formed from (2.17), (2.19), and (2.21). Alternative choices of the weighting matrix $W_{N}$ yield estimators with varying degrees of asymptotic efficiency. Amongst the estimators that minimize criterion (2.23), the choice of $W_{N}$ yielding the smallest asymptotic covariance matrix is $V^{-1}$. Using this optimal weighting matrix, $\Lambda$ is given by $\left(D^{\prime} V^{-1} D\right)^{-1}$. (See Ferguson (1958) and Hansen (1982).) Consistent estimates of $D$ and $V$ are obtained by replacing expectations with their respective sample means evaluated at the estimated values of $\pi$ and $\boldsymbol{\kappa}_{i}$.

In both the LIML and joint GMM estimation strategies just described, we must jointly estimate the elements of $\underset{\sim}{\pi}$ and $\left\{{\underset{\sim}{\boldsymbol{\kappa}}}_{i}\right\}_{i=1}^{N}$, since the latter are unknown. Estimation of the fixed effects presents no new problems operationally; estimators can be formed by setting the score functions for each element in $\left\{\boldsymbol{\kappa}_{i}\right\}_{i=1}^{N}$ to zero. But, in our particular application, the estimation of fixed effects does introduce some new issues. First, for women who never work during the 
sample period, the fixed effect in their labor supply equations are unbounded and one cannot estimate fixed effects in their wage equations since wages are not observed for this group. Accordingly, our sample is restricted to women who have worked at least once during the sample period. ${ }^{9}$ Second, consistency of the estimators for $\underset{\tilde{d}}{\boldsymbol{\pi}}$ and $\left\{\boldsymbol{\kappa}_{i}\right\}_{i=1}^{N}$ requires that both the number of time periods for each household, $T$, and $N T$ become large. For the sample analyzed in our empirical application, the number of time periods per household is (at most) 10 . This begs the question of whether our estimates suffer from small sample bias. Because the model is nonlinear, the issue of small sample bias is not only relevant for the fixed effect estimators but also for the estimators of the other parameters. Whether this is a serious matter cannot be answered a priori since all samples are finite and many cannot be imagined to become infinite. What we should like to know is how useful a guide asymptotic theory provides in this application.

One attempt to examine the small sample properties of estimators similar to those herein has been undertaken by Heckman (1981). He presents results of a Monte Carlo study of the properties of a maximum likelihood fixed effect estimator for a probit model with 8 time periods per observation. For a model which includes a single exogenous regressor (i.e., uncorrelated with the fixed effect and the serially uncorrelated disturbance component), he finds the estimated parameter values are very close to the true parameter values. The fixed effect estimator does show evidence of small sample bias in a probit model with a fixed effect for data generated by a discrete, first-order Markov process. Our specification differs from Heckman's in two important respects. First, the labor supply equation in our model is actually a Tobit specification (a combination of a linear regression model and a probit equation). ${ }^{10}$ Second, our birth outcomes are not generated by the Markov process used in Heckman's analysis; rather they arise from a two stage process involving the index function governing contraception behavior and, conditional on the contraceptive choice, independent stochastic processes determining the occurrence of births.

Given the mixed nature of Heckman's findings and that our model specification differs somewhat from his, we undertook a limited Monte Carlo study to investigate the small sample performance of the estimation strategy used in our empirical work. (It is fully described in the Appendix.) We constructed 25 independent samples with sample sizes of 50 and 200 households. The data in each sample were generated by a model for which $\psi_{k}=\psi_{1}, \gamma_{k}=\gamma_{1} \delta^{k-1}$, for all $k$, the $\tilde{\nu}_{4 k}$ 's were not constrained to be equal for all $k$, and births were stochastic events with probabilities which depended upon parental contraceptive choices. (The values used for the parameters are given in the Appendix.) We then estimated the labor supply and labor force participation equations given in (2.1)

\footnotetext{
${ }^{9}$ Heckman and MaCurdy (1980) account for this type of sample selection in estimating a model of female labor supply and wage equations using the same data set as in this study. They find that their estimates are not sensitive to whether the correction is made. Therefore, this potential source of selection bias is ignored here.

${ }^{10}$ Heckman and MaCurdy (1980) conjecture that the problem of small sample bias in fixed effect estimators for Tobit specifications may be less than for the probit case.
} 
and (2.2) using data from 10 consecutive periods for each household as well as information on previous births. The means of the resulting parameter estimates were then compared with the true parameters and with estimates obtained by including the true fixed effects as regressors in these equations. (Consistency from the latter estimates only requires $N$ to approach infinity.) For sample sizes of 50 households, evidence of small sample bias in the parameter estimates was found when the fixed effects were estimated. Part of this bias, though, is attributable to the small number of households, since the estimates obtained using the true fixed effects as regressors were also biased (generally in the same direction as when the fixed effects were estimated). Moreover, when $N=50$, all of the parameter estimates when the fixed effects were estimated were within one to two standard deviations of the true parameters. With samples of $N=200$, the extent of bias was reduced, although not completely eliminated. Again, the means of the resulting estimates were generally within one to two standard deviations of the true parameter values. This evidence is by no means conclusive. Nevertheless, these results suggest that asymptotic theory has a role to play when interpreting the parameter estimates in this application.

The empirical results presented in the next section actually were obtained from the following two stage estimation procedure. We first obtained estimates of the parameters $\pi_{1}, \pi_{2}$, and $\left\{\boldsymbol{\kappa}_{i}\right\}_{i=1}^{N}$ for the labor supply, wage, and child care components maximizing the log-likelihood function formed by summing (2.17) and (2.19) across households. Note that the resulting estimators are FIML for these three equations when the disturbance in (2.16) is assumed to be normally distributed. In the second stage, we estimated alternative restricted versions of $\pi$ by maximizing (2.23) with respect to $\pi$, where we substituted the first stage estimates of the fixed effects, i.e., $\left\{\hat{\boldsymbol{\kappa}}_{i}\right\}_{i=1}^{N^{\sim}}$, for the true fixed effects. The covariance matrices for the second stage estimators should be corrected for the first stage estimation error. However, the correction was not made in our analysis because it involves inverting matrices of an order given by the number of observations, $N$, plus the dimension of the parameter vector, $\pi$.

\section{EMPIRICAL RESULTS}

The data used are taken from the Panel Study of Income Dynamics (PSID), a longitudinal survey in which over 5000 households have been interviewed annually since 1968 . To be included in our empirical analysis, households from the PSID had to meet the following criteria: (i) the same husband and wife headed the household in 1970 through 1979, (ii) the wife was less than 40 years old in 1980, (iii) the wife worked in the labor force one or more years between 1970 and 1979, and (iv) the household had at least one birth prior to 1979.

If a sample household's first birth occurred prior to 1970, we utilized all 10 years of the panel data but when the first birth occurred after 1970, only data for years subsequent to that event were utilized. (Consequently the number of households increases over the ten year period from 328 to 351.) For each household in the sample $(i=1, \ldots, N)$, we have data on: (i) the wife's age, $t_{i}$; (ii) 
TABLE I

SAMPle Means of PSID Data

(Standard Deviations in Parentheses.)

\begin{tabular}{cccccccccc}
\hline \hline Year & $\begin{array}{c}\text { Sample } \\
\text { Size }\end{array}$ & $d_{i t}$ & $h_{i t}$ & $w_{i t}$ & $v_{i t}$ & $n_{i t}^{\mathrm{a}}$ & $b_{i t}$ & $t_{i}$ & $\tilde{c}_{i t}$ \\
\hline 1970 & 328 & 0.555 & 0.598 & 2.002 & 7.176 & 2.287 & 0.113 & 25.866 & \\
& & $(0.497)$ & $(0.778)$ & $(1.443)$ & $(4.090)$ & $(1.310)$ & $(0.316)$ & $(3.483)$ & \\
1971 & 336 & 0.580 & 0.645 & 2.035 & 7.478 & 2.366 & 0.113 & 26.810 & \\
& & $(0.494)$ & $(0.789)$ & $(1.274)$ & $(4.405)$ & $(1.312)$ & $(0.317)$ & $(3.514)$ & \\
1972 & 339 & 0.537 & 0.647 & 2.231 & 8.092 & 2.466 & 0.086 & 27.773 & \\
& & $(0.499)$ & $(0.808)$ & $(1.556)$ & $(4.536)$ & $(1.317)$ & $(0.280)$ & $(3.521)$ & \\
1973 & 346 & 0.587 & 0.724 & 2.594 & 8.382 & 2.520 & 0.058 & 28.714 & \\
& & $(0.492)$ & $(0.833)$ & $(3.519)$ & $(4.503)$ & $(1.311)$ & $(0.233)$ & $(3.529)$ & \\
1974 & 347 & 0.588 & 0.716 & 2.245 & 8.112 & 2.573 & 0.043 & 29.706 & \\
& & $(0.492)$ & $(0.819)$ & $(1.510)$ & $(4.757)$ & $(1.314)$ & $(0.203)$ & $(3.527)$ & \\
1975 & 348 & 0.647 & 0.785 & 2.402 & 8.108 & 2.612 & 0.049 & 30.701 & \\
& & $(0.478)$ & $(0.838)$ & $(2.236)$ & $(5.279)$ & $(1.309)$ & $(0.216)$ & $(3.523)$ & \\
1976 & 350 & 0.643 & 0.818 & 2.566 & 8.688 & 2.649 & 0.051 & 31.700 & 0.745 \\
& & $(0.479)$ & $(0.827)$ & $(2.339)$ & $(6.140)$ & $(1.289)$ & $(0.221)$ & $(3.518)$ & $(0.942)$ \\
1977 & 350 & 0.660 & 0.865 & 2.477 & 8.995 & 2.697 & 0.040 & 32.700 & \\
& & $(0.474)$ & $(0.846)$ & $(2.249)$ & $(6.120)$ & $(1.298)$ & $(0.196)$ & $(3.518)$ & \\
1978 & 351 & 0.718 & 0.972 & 2.270 & 9.325 & 2.726 & 0.037 & 33.675 & \\
& & $(0.431)$ & $(0.832)$ & $(1.607)$ & $(6.244)$ & $(1.298)$ & $(0.189)$ & $(3.543)$ & \\
1979 & 351 & 0.789 & 1.081 & 2.369 & 8.691 & 2.755 & 0.009 & 34.675 & \\
& & $(0.408)$ & $(0.837)$ & $(2.152)$ & $(5.487)$ & $(1.273)$ & $(0.092)$ & $(3.543)$ & \\
\hline
\end{tabular}

$\Sigma^{K}$ This variable denotes the number of existing children in the household as of year $t$, i.e., $n_{i t}=$ $\sum_{r-1}^{K} b_{i, t-r}$.

its entire birth history through 1979; (iii) whether or not the wife worked, $d_{i t}$, in each year, and, if she worked, her annual hours of work, $h_{i t}$ (in thousands of hours); (iv) the mother's market wage rate, $w_{i t}$ (in 1968 dollars), for each year in which she worked; (v) the mother's answer to a question, asked in 1976, about how many hours she spent caring for her children that year, $\tilde{c}_{i \tau}$ (in thousands of hours); and (vi) the father's annual taxable income, $y_{i t}$ (in thousands of 1968 dollars).

Table I reports sample statistics on these variables and the number of households included in each of the 10 years.

By jointly estimating the labor supply, wage, and mother's child care time equations, we can identify the processes governing $a_{i t}$ and $c_{i t}$ (see equations (2.4) and (2.5)). In their most general forms, the mother's time devoted to child care and the market input maintenance costs can vary with the age of an existing child. As noted above, empirical studies have found that maternal time inputs decline as children age. We test for this pattern along with the restriction that market input costs are age-invariant from these first stage estimates. That is, we test whether

$$
\left(\gamma_{k}, \psi_{k}\right)=\left(\gamma_{1} \delta^{k-1}, \psi_{1}\right) \text { for } k \leqslant 23
$$

where we include up to 23 lags in births since the age of the oldest child in our sample as of 1979 is 23 . In terms of the ${\underset{\sim}{1}}_{1}$ and ${\underset{\sim}{2}}_{2}$ vectors, the restrictions in (3.1) 
are equivalent to setting

$$
\pi_{1 k}=\pi_{11}\left(\frac{\pi_{12}}{\pi_{11}}\right)^{k-1} \text { for } 3 \leqslant k \leqslant 23,
$$

and

$$
\pi_{2,4+k}=\pi_{25}+\pi_{11}\left[\frac{\pi_{26}-\pi_{25}}{\pi_{12}-\pi_{11}}\right]\left[\left(\frac{\pi_{12}}{\pi_{11}}\right)^{k-1}-1\right] \text { for } 3 \leqslant k \leqslant 23 .
$$

ML estimates of the labor supply, wage, and child care equations are reported in Table II. Estimates based on unrestricted maternal time and market input cost specifications are found in Column A of this table; those corresponding to (3.1) are found in Column B. Comparing the restricted and unrestricted specifications via a likelihood ratio test, the restrictions in (3.1) are not rejected using conventional critical values. (The test statistic is 40.8 and the associated level of significance is 0.524 .) Thus, the data cannot reject the hypothesis that annual expenditures on children are age-invariant, and maternal child care time inputs decline geometrically as children age. Accordingly, we maintained specification (3.1) for $a_{i t}$ and $c_{i t}$ in the estimation of the full model. ${ }^{11}$

GMM estimates obtained by jointly estimating the labor supply, wage, child care and probability of birth functions are reported in Table III. Because there are relatively few older children in the sample, we encountered numerical problems in estimating specifications of the contraception index function when all the coefficients on lagged births were left unrestricted. For this reason, all estimates of the contraception index function reported in Table III restrict the effects of children older than 11 to be the same apart from differences in child care requirements. That is, $\tilde{\nu}_{4 k}=\tilde{\nu}_{4,11}$ for $k \geqslant 11$. Also note that the estimated coefficients on the lagged births in the $\nu_{i t}$ function presented in Table III measure the combined influence on parental contraceptive choice of expenditures on existing children, $\tilde{\nu}_{3} \psi_{1}$, and of the utility such children provide parents, $\tilde{\nu}_{4 k}$, for all $k$. Even though our estimates from the labor supply equation suggest that $a_{i t}$ is age-invariant, without a direct measure on such expenditures, we cannot separately identify these two effects on $\nu_{i t}$.

${ }^{11}$ To examine the robustness of these findings, we also investigated the appropriateness of a number of assumptions made in the mother's labor supply, wage, and child care equations. For example, as noted in Section 2, the specification of the process of maternal child care does not allow for substitution of the mother's time for other inputs in caring for children. We re-estimated the child care equation including measures of the husband's and mother's wage rates (accounting for women who were not working in 1976) as well as the lagged birth variables. We could not reject the hypothesis that the effects of these wages on the hours the wife spends in child care are zero. We also examined whether the mother's age had an independent influence on her labor supply, by adding that variable to the above specification; the estimated coefficient on this variable was positive but insignificant. Finally, we examined whether our results were sensitive to the inclusion of fixed effects in the mother's labor supply and/or wage equations by eliminating these effects and re-estimating the equations. By a likelihood ratio test, the inclusion of the $\kappa_{i}$ 's significantly improved the fit of these two equations, but the coefficient estimates and significance on the remaining variables were not noticably affected by the removal. 


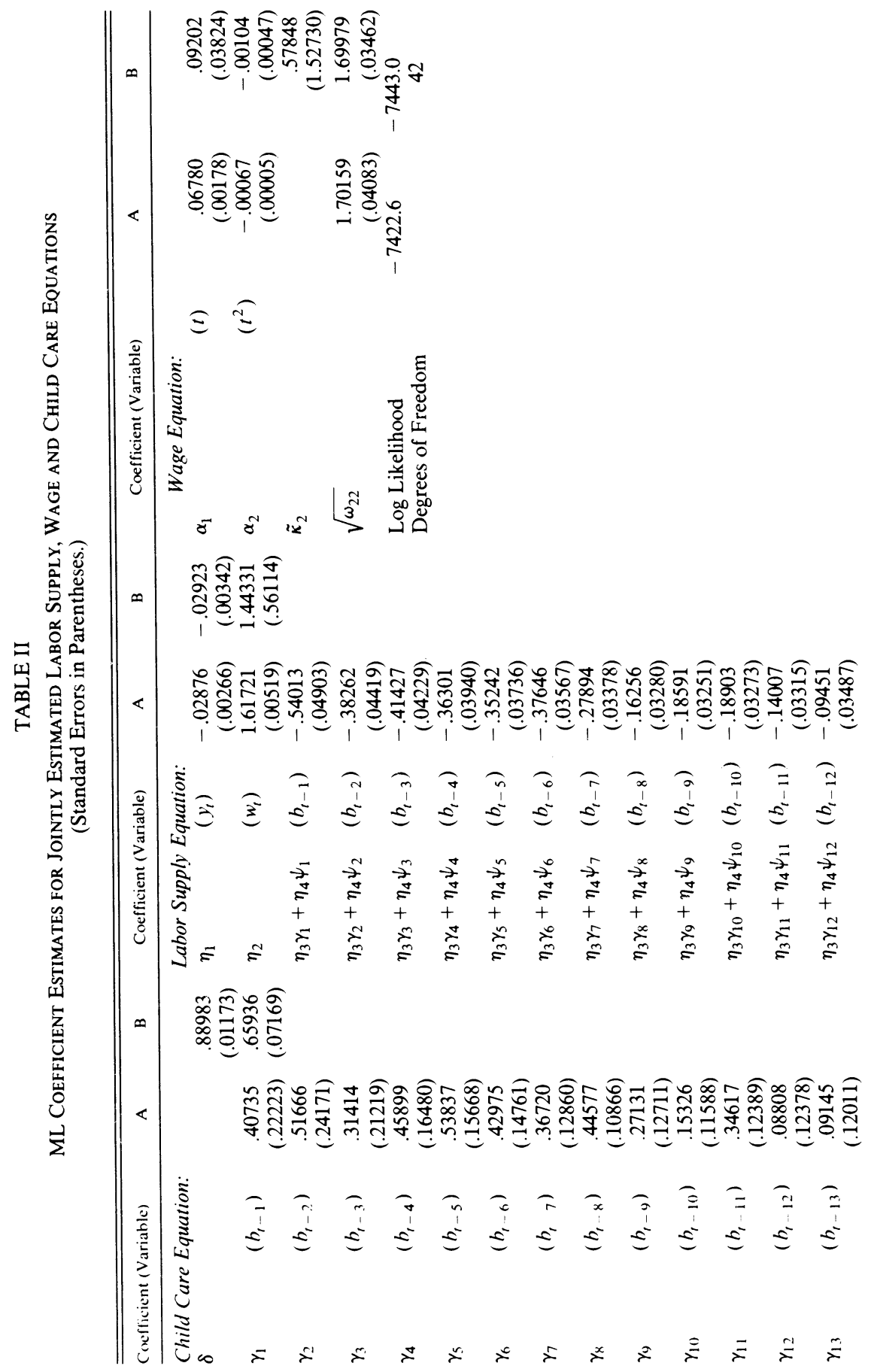




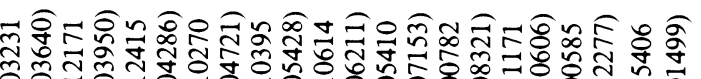

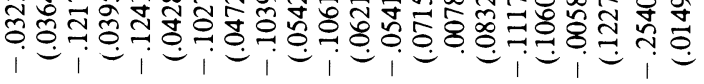

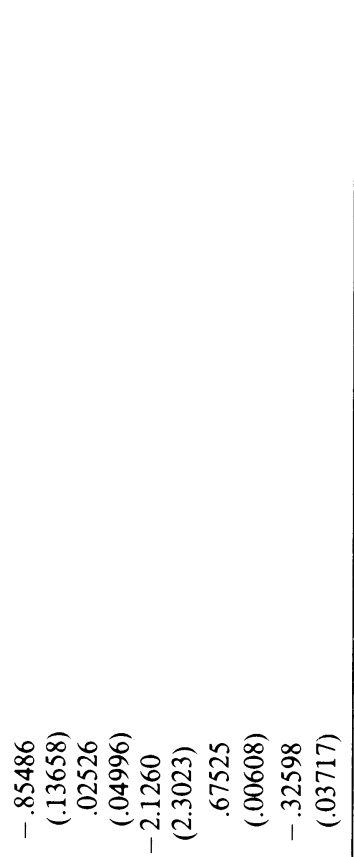

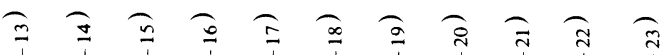

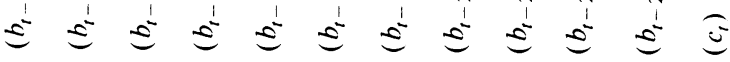

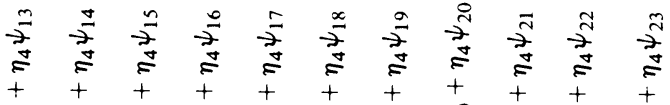

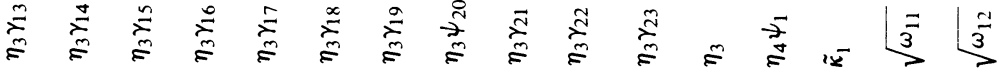

迅

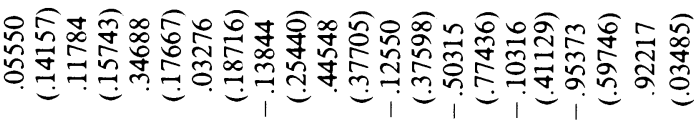

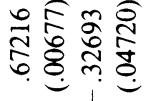

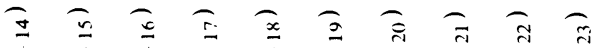

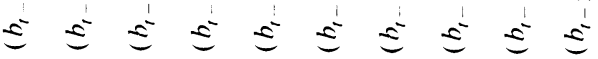

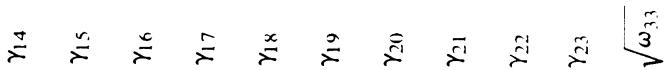


TABLE III

GMM CoffFicient Estimates for Jointly Estimated Child CARe, Labor Supply, Wage AND CONTRACEPTION INDEX FUNCTION EQUATIONS AND PRobability ESTIMATES FOR CONTRACEPTION METHODS

(Standard Errors in Parentheses.)

\begin{tabular}{|c|c|c|c|c|c|c|}
\hline \multicolumn{2}{|c|}{ Coefficient (Variable) } & A & B & Coefficient (Variable) & A & B \\
\hline & \multicolumn{3}{|l|}{ Contraception Index Function: } \\
\hline \multicolumn{2}{|c|}{$\delta$} & $\begin{array}{c}.88318 \\
(.01485)\end{array}$ & $\begin{array}{l}.90188 \\
(.01483)\end{array}$ & $\tilde{\nu}_{0}$ & $\begin{array}{l}1.91429 \\
(.02958)\end{array}$ & $\begin{array}{l}5.33593 \\
(.05137)\end{array}$ \\
\hline \multicolumn{2}{|l|}{$\gamma_{1}$} & $\begin{array}{c}.63525 \\
(.08658)\end{array}$ & $\begin{array}{l}.52597 \\
(.07153)\end{array}$ & $\left(y_{t}\right)$ & $\begin{array}{c}.01490 \\
(.00778)\end{array}$ & $\begin{array}{c}-.02213 \\
(.19527)\end{array}$ \\
\hline \multicolumn{2}{|l|}{$\sqrt{\omega_{33}}$} & $\begin{array}{l}.91130 \\
(.04673)\end{array}$ & $\begin{array}{l}.94310 \\
(.04795)\end{array}$ & $\left(c_{t}\right)$ & $\begin{array}{r}-4.97306 \\
(1.59622)\end{array}$ & $\begin{array}{l}5.26513 \\
(.80261)\end{array}$ \\
\hline \multicolumn{7}{|c|}{ Labor Supply Equation: } \\
\hline & & & & $\tilde{\nu}_{3} \psi_{1}+\tilde{\nu}_{41} \quad\left(b_{t-1}\right)$ & $\begin{array}{c}1.21097 \\
(1.05307)\end{array}$ & $\begin{array}{r}-2.23759 \\
(.22177)\end{array}$ \\
\hline$\eta_{1}$ & $\left(y_{t}\right)$ & $\begin{array}{r}-.03072 \\
(.00206)\end{array}$ & $\begin{array}{r}-.02925 \\
(.00182)\end{array}$ & $\tilde{\nu}_{3} \psi_{1}+\tilde{\nu}_{42} \quad\left(b_{t-2}\right)$ & $\begin{array}{l}2.41938 \\
(.91675)\end{array}$ & \\
\hline$\eta_{2}$ & $\left(w_{t}\right)$ & $\begin{array}{l}1.45597 \\
(.01392)\end{array}$ & $\begin{array}{l}1.44454 \\
(.01362)\end{array}$ & $\tilde{\nu}_{3} \psi_{1}+\tilde{\nu}_{43} \quad\left(b_{t-3}\right)$ & $\begin{array}{l}2.83447 \\
(.79458)\end{array}$ & \\
\hline$\eta_{3}$ & $\left(c_{t}\right)$ & $\begin{array}{r}-.87634 \\
(.14267)\end{array}$ & $\begin{array}{r}-1.09960 \\
(.20403)\end{array}$ & $\tilde{\nu}_{3} \psi_{1}+\tilde{\nu}_{44} \quad\left(b_{t-4}\right)$ & $\begin{array}{l}2.35476 \\
(.69393)\end{array}$ & \\
\hline \multicolumn{2}{|l|}{$\eta_{4} \psi_{1}$} & $\begin{array}{c}.00883 \\
(.00289)\end{array}$ & $\begin{array}{l}.05386 \\
(.04051)\end{array}$ & $\tilde{\nu}_{3} \psi_{1}+\tilde{\nu}_{45} \quad\left(b_{t-5}\right)$ & $\begin{array}{l}1.76421 \\
(.60676)\end{array}$ & \\
\hline \multicolumn{2}{|l|}{$\sqrt{\omega_{11}}$} & $\begin{array}{l}.69356 \\
(.02525)\end{array}$ & $\begin{array}{l}.66905 \\
(.02376)\end{array}$ & $\tilde{\nu}_{3} \psi_{1}+\tilde{\nu}_{46} \quad\left(b_{t-6}\right)$ & $\begin{array}{l}1.00470 \\
(.49497)\end{array}$ & \\
\hline \multicolumn{2}{|l|}{$\sqrt{\omega_{12}}$} & $\begin{array}{r}-.32774 \\
(.00434)\end{array}$ & $\begin{aligned}-.32571 \\
(.00433)\end{aligned}$ & $\tilde{\nu}_{3} \psi_{1}+\tilde{\nu}_{47} \quad\left(b_{t-7}\right)$ & $\begin{array}{l}.51514 \\
(.44724)\end{array}$ & \\
\hline \multicolumn{7}{|c|}{ Wage Equation: } \\
\hline$\alpha_{1}$ & $(t)$ & $\begin{array}{c}.09175 \\
(.00127)\end{array}$ & $\begin{array}{c}.09205 \\
(.00127)\end{array}$ & $\tilde{\nu}_{3} \psi_{1}+\tilde{\nu}_{48} \quad\left(b_{t-8}\right)$ & $\begin{array}{l}-.15155 \\
(.40921)\end{array}$ & \\
\hline$\alpha_{2}$ & $\left(t^{2}\right)$ & $\begin{array}{c}-.00103 \\
(.00041)\end{array}$ & $\begin{array}{c}-.00104 \\
(.00042)\end{array}$ & $\tilde{\nu}_{3} \psi_{1}+\tilde{\nu}_{49} \quad\left(b_{t-9}\right)$ & $\begin{array}{l}.79073 \\
(.35450)\end{array}$ & \\
\hline \multicolumn{2}{|l|}{$\sqrt{\omega_{22}}$} & $\begin{array}{l}1.57699 \\
(.09334)\end{array}$ & $\begin{array}{l}1.71785 \\
(.10474)\end{array}$ & $\tilde{\nu}_{3} \psi_{1}+\tilde{\nu}_{4,10}\left(b_{t-10}\right)$ & $\begin{array}{l}.00883 \\
(.02873)\end{array}$ & \\
\hline \multicolumn{7}{|c|}{ Probabilities for Contraception Methods: } \\
\hline & & & $\tilde{\nu}_{3} \psi_{1}+\tilde{\nu}_{4,11}\left(b_{t-11} \cdots b_{t-23}\right)$ & $\begin{array}{l}1.10412 \\
(.02750)\end{array}$ & \\
\hline \multirow{2}{*}{\multicolumn{2}{|c|}{$\underline{p}$}} & .02218 & .05204 & $(t)$ & -.07190 & -.16146 \\
\hline & & $(.00319)$ & $(.01321)$ & & $(.00570)$ & $(.01378)$ \\
\hline \multirow[t]{3}{*}{$\bar{p}$} & & $\begin{array}{c}.30414 \\
(.02841)\end{array}$ & $\begin{array}{c}.14614 \\
(.01991)\end{array}$ & $\left(\kappa_{1}\right)$ & $\begin{array}{c}-.04771 \\
(.07045)\end{array}$ & $\begin{array}{r}-.56631 \\
(.21372)\end{array}$ \\
\hline & & & & $\tilde{\boldsymbol{\nu}}_{7} \quad\left(\kappa_{2}\right)$ & $\begin{array}{r}-.02472 \\
(.04650)\end{array}$ & $\begin{array}{r}-.09217 \\
(.16472)\end{array}$ \\
\hline & & & & 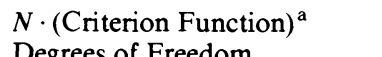 & 64.4 & 89.9 \\
\hline
\end{tabular}

Notes: Column A-Estimates for specification (3.4). Column B-Estimates for specification (3.6)

a The criterion function is the value of $(2.23)$. 
Estimates in Column A of Table III maintain the assumptions of declining maternal child care with the age of the children and the age-invariant market input expenditures in the labor supply equation, but allow the other effects of children under the age of 11 to vary freely with age. That is, these estimates correspond to the specification

$$
\left(\gamma_{k}, \psi_{k}, \tilde{\nu}_{4 k}\right)=\left\{\begin{array}{l}
\left(\gamma_{1} \delta^{k-1}, \psi_{1}, \tilde{\nu}_{4 k}\right) \text { for } k<11, \\
\left(\gamma_{1} \delta^{k-1}, \psi_{1}, \tilde{\nu}_{4,11}\right) \text { for } 11 \leqslant k \leqslant 23
\end{array}\right.
$$

which is equivalent to imposing the restrictions given in (3.2) and (3.3) on $\pi_{1}$ and $\pi_{2}$ and the following restrictions involving $\pi_{3}$ :

$$
\pi_{3, k+4}=\pi_{3,15}+\pi_{11}\left[\frac{\pi_{3,16}-\pi_{3,15}}{\pi_{12}-\pi_{11}}\right]\left[\left(\frac{\pi_{12}}{\pi_{11}}\right)^{k-1}-1\right] \text { for } 13 \leqslant k \leqslant 23 .
$$

Within the GMM estimation procedure, one can test the over-identifying restrictions implied by specification (3.4). ${ }^{12}$ The statistics are reported in Table III. The value of this statistic for (3.4) is 64.4 and the associated degrees of freedom are 54 . The level of significance of this test is .157 ; thus, using conventional critical values, we cannot reject specification (3.4).

Column B of Table III contains estimates of the full model in which the influence of existing children, net of child care costs, on parental contraceptive choice depends only upon their number and does not vary with their ages. This specification assumes that

$$
\left(\gamma_{k}, \psi_{k}, \tilde{v}_{4 k}\right)=\left(\gamma_{1} \delta^{k-1}, \psi_{1}, \tilde{v}_{41}\right) \text { for } k \leqslant 23 .
$$

In terms of restrictions on $\underset{\sim}{\pi}$, (3.6) implies that we impose the following set of restrictions in place of (3.5):

$$
\pi_{3, k+4}=\pi_{35}+\pi_{11}\left[\frac{\pi_{36}-\pi_{35}}{\pi_{12}-\pi_{11}}\right]\left[\left(\frac{\pi_{12}}{\pi_{11}}\right)^{k-1}-1\right] \text { for } 3 \leqslant k \leqslant 23 .
$$

Specification (3.6) receives little support from the data. The test of imposing the restrictions implied by this commonly assumed specification is rejected at the .05 significance level. (The test statistic is 89.0 with 64 degrees of freedom and the level of significance is .021.) In addition, since (3.6) is nested within (3.4), a test imposing the additional 10 restrictions can also be performed. The test statistic is given by the product of $N$ and the difference in the values of the criterion function for the respective specifications. Its value is 24.6 , which with 10 degrees of freedom, has a level of significance of .006 ; thus we reject these additional restrictions at conventional cutoff levels.

To summarize, the test results suggest the following conclusions: (a) maternal time inputs in the care of children decline as children age; (b) parental expendi-

\footnotetext{
${ }^{12}$ See Hansen (1982). The test is based on the fact that under the null hypothesis, $N$ times the optimally weighted criterion function in (2.23) is asymptotically $\chi^{2}$ distributed with degrees of freedom equal to the number of overidentifying restrictions.
} 
tures on market inputs to children do not significantly vary with the ages of offspring; ${ }^{13}$ and (c) net of their influence of costs, the additional effects of existing children on contraceptive choice depend not only on the number of children but also on their age distribution. Moreover, a model which incorporates these features, and their implied cross-equation restrictions, cannot be rejected with our data.

We now turn to an examination of the parameter estimates themselves. First consider the estimates for the child care equations shown in Tables II and III. From the estimates of the $\left(\gamma_{1}, \delta\right)$ specification, we infer that the amount of maternal time required to care for a newborn child, is about 660 hours per year, and is declining geometrically at the annual rate of around 12 per cent. Observe that both $\hat{\delta}$ and $\hat{\gamma}_{1}$ are always significant and that $\hat{\delta}$ is also significantly different from 1, indicating that the maternal child care time declines as children age.

With respect to the labor supply equation, the estimated effects of the husband's income are consistently negative and significant, while those of the mother's wage are positive and significant. Furthermore, the estimates of these effects are robust to the alternative specifications for $a_{i t}$ and $c_{i t}$. The elasticity of a mother's labor supply with respect to changes in her wage rate is around 1.23; the mother's labor supply elasticity with respect to her spouse's income is around -.44 . Note that our estimate of the wage elasticity is roughly half of that found in Heckman and MaCurdy $(1980,1982)^{14}$ who estimate a life cycle specification of female labor supply and wages with panel data from the PSID. From Column B of Table II and the results in Table III, we find that the greater the mother's commitment to child care, i.e., greater $c_{i t}$, the lower her labor supply, and, assuming that market expenditures on child care are positive, i.e., $\psi_{1}>0$, the larger the existing number of children, the greater her labor supply (although the latter effect is not generally statistically significant). Such results are consistent with previous empirical studies of female labor supply (see, for example, Cain (1966), Schultz (1978), and Cogan (1980)) which find that younger children have a negative effect on female labor supply while the presence of older children have a positive effect. In our formulation, this pattern arises because $c_{i t}$ and $a_{i t}$ have opposite effects on female labor supply and the care of older children is less time-intensive than for younger children. With respect to the effect of $c_{i t}$, note that the estimates indicate that increases in time devoted to child care do not reduce labor supply one for one; rather, increasing child care responsibilities also reduce the mother's time in other nonmarket activities. If we assume that a dollar reduction in the household's income is equivalent to a dollar increase in their child care expenditures, ${ }^{15}$ then $\eta_{4}=-\eta_{1}$ and we can obtain an estimate of $\psi_{1}$, the annual per capita expenditures on children, by dividing our estimate of $\eta_{4} \psi_{1}$ by that for $-\eta_{1}$. The estimated expenditures range from $\$ 287$ to $\$ 1,841$ annually per child, based on

\footnotetext{
${ }^{13}$ This finding should be interpreted with some caution since, unlike the mother's child care time inputs, we have no direct information in our sample on actual expenditures on children.

${ }^{14}$ Their corrected set of estimates, reported in Heckman and MaCurdy (1982), yield an estimated labor supply elasticity of 2.23 .

${ }^{15}$ See the model outlined in Hotz and Miller (1986).
} 
1968 prices, where the upper limit is for the model rejected by the data. Finally, note that the fixed effect in this equation, $\kappa_{1}$, exhibits a good deal of variation across households (as measured by its sample standard deviation). ${ }^{16}$

With respect to the wage equation, we find, across the alternative specifications, that the estimated wage profile of the mother exhibits a concave shape over the life cycle, peaking at about 44 years of age. As with the $\kappa_{1}$, the householdspecific component to her market wage rate, $\kappa_{2}$, exhibits a good deal of variation across the sample of women. ${ }^{17}$

Estimates from the determinants of the birth probability equation are shown in Table III. Regardless of the specification, the estimates of both $\underline{p}$ and $\bar{p}$ are precisely estimated and the hypothesis that $p=0$ and $\bar{p}=1$ is rejected. These estimates suggest that there is a significant stochastic component affecting the life cycle timing of births. Our annual probability of conception when no contraception is practiced, implies a monthly conception probability of around 2.5 per cent. While this is somewhat low relative to those from natural fertility populations (see Sheps and Menken (1973)), we note that Rosenzweig and Schultz (1985) obtain the same estimate for a sample of U.S. households using data on couples' actual contraceptive practices.

While births are not perfectly controllable, we can reject the hypothesis that $p=\bar{p}$, indicating that the life cycle timing of births is affected by parental contraceptive choice. With respect to the contraception index function governing these choices, we find that the estimates in Column A of Table III for specification (3.4) are intuitively plausible. The coefficient on $c_{i t}$ is negative indicating that the less time a mother has available due to child care demands, the higher the household's marginal cost and so the desire for having more children is lower. The coefficient estimate for $y_{i t}$ is negative indicating that raising the father's income reduces the marginal utility loss of expenditures on additional children. Both of these effects are statistically significant, although the income elasticity on the birth probability is relatively small. (Evaluated at the means of the data, this elasticity is 0.02 .) As measured by the coefficient on $\kappa_{2}$ in $\nu_{i t}$, women with higher permanent wages have lower desires for children via a price-of-time effect; in addition, the permanent household-specific component, $\kappa_{1}$ (which enters positively in the female's labor supply equation by construction), also has a negative effect on the probability of conception. Note, however, that both of these latter effects are insignificant and that their estimated elasticities are quite small (.007 for $\kappa_{1}$ and -.004 for $\kappa_{2}$ ). The estimated effect of the mother's age is negative. As

\footnotetext{
${ }^{16}$ In a separate analysis, we regressed $\kappa_{1}$ on a number of time invariant characteristics of the household. We found that $\kappa_{1}$ was negatively related to the mother's educational attainment, whether she had an advanced degree, the husband's educational attainment, and whether the husband was from an earlier birth cohort (as measured by his age in 1979), while it was positively related to whether the husband had an advanced degree, the earlier the wife's birth cohort, and the 10-year average local unemployment rate. All but the latter two effects were significant by a standard $t$ test on the estimated coefficients.

${ }^{17}$ We also ran regressions for $\kappa_{2}$ and found it to be negatively related to the mother being from an earlier birth cohort and positively related to the wife's educational attainment, whether she had an advanced degree, and the average local unemployment rate; only the latter was not significant.
} 
mentioned above, this effect likely reflects two influences which we cannot separate: variation in the desire for children as the household moves closer to the end of its fecund period and the impact of anticipated future wage changes for the mother. The combined effect implies that the household's desire to have more children declines as the mother ages. Finally, net of the effect of $c_{i t}$, many of the estimated coefficients on lagged births are also significant and vary with the ages of existing children. Recall that these estimates measure the combined impact of the parent's utility from existing children and of the market expenditures required in their care on the desire for an additional child. Examining the estimates for lags of different length, we find that the effects increase sharply to lag $t-3$, and then gradually decline, converging to a value below their initial point. Past age three, as children grow up, they increase the likelihood that the parents will contracept. ${ }^{18}$

Examining the estimates in Column B of Table III, we find that imposing the rejected specification (3.6) in which the additional effects of lagged births are assumed to be age-invariant reduces the impact the index has on birth outcomes because the estimate of $\bar{p}$ approaches $p$. These rejected restrictions end up attributing a larger proportion of births to chance rather than choice. Moreover, the coefficient on husband's income, $\tilde{\nu}_{1}$, becomes significantly negative under (3.6). Similarly, the sign on the maternal child care effect, $\tilde{\nu}_{2}$, is also reversed. Thus, when these unsupported restrictions are imposed on the data, the economically plausible results that emerge under specification (3.4) are turned on their heads.

To illustrate how our estimates of the stochastic process describing fertility behavior depend on the hypothesized specification, we present the following simulations. We calculated the birth hazard of the waiting time to the third child of a representative household in which the first two births were assumed to have occurred at age 20 and 22, respectively (these were mean ages for the first two births in our sample), and that the mother's fixed effects as well as her husband's income at age 22 correspond to sample means for women of that age. To forecast the husband's subsequent earnings, we estimated a linear regression equation for annual earnings as a function of his educational attainment, age, and age squared and allowed the regression disturbance to be autoregressive of order one. The resulting estimates were

$$
\begin{aligned}
& y_{i t}=-19.028+.9163 \mathrm{EDUC}_{i}+.8827 \mathrm{AGE}_{i}-.0113 \mathrm{AGE}_{i}^{2}+e_{i t} \text {, } \\
& \text { (8.887) (.1165) } \\
& \text { (.4418) } \\
& \text { (.0050) } \\
& e_{i t}=.8326 e_{i, t-1}+v_{i t}, \quad \operatorname{Var}\left(v_{i t}\right)=7.746, \quad R^{2}=.728 \text {, } \\
& \text { (.0108) }
\end{aligned}
$$

where the estimated coefficient standard errors are in parentheses. Optimal linear unbiased forecasts of husband's annual income, subsequent to the second birth,

\footnotetext{
${ }^{18}$ The small value of the coefficient on $b_{t-1}$ relative to those on $b_{t-2}$ and $b_{t-3}$ may also reflect the reduction of woman's risk of pregnancy after a birth during the post-partum amenorrheic period.
} 


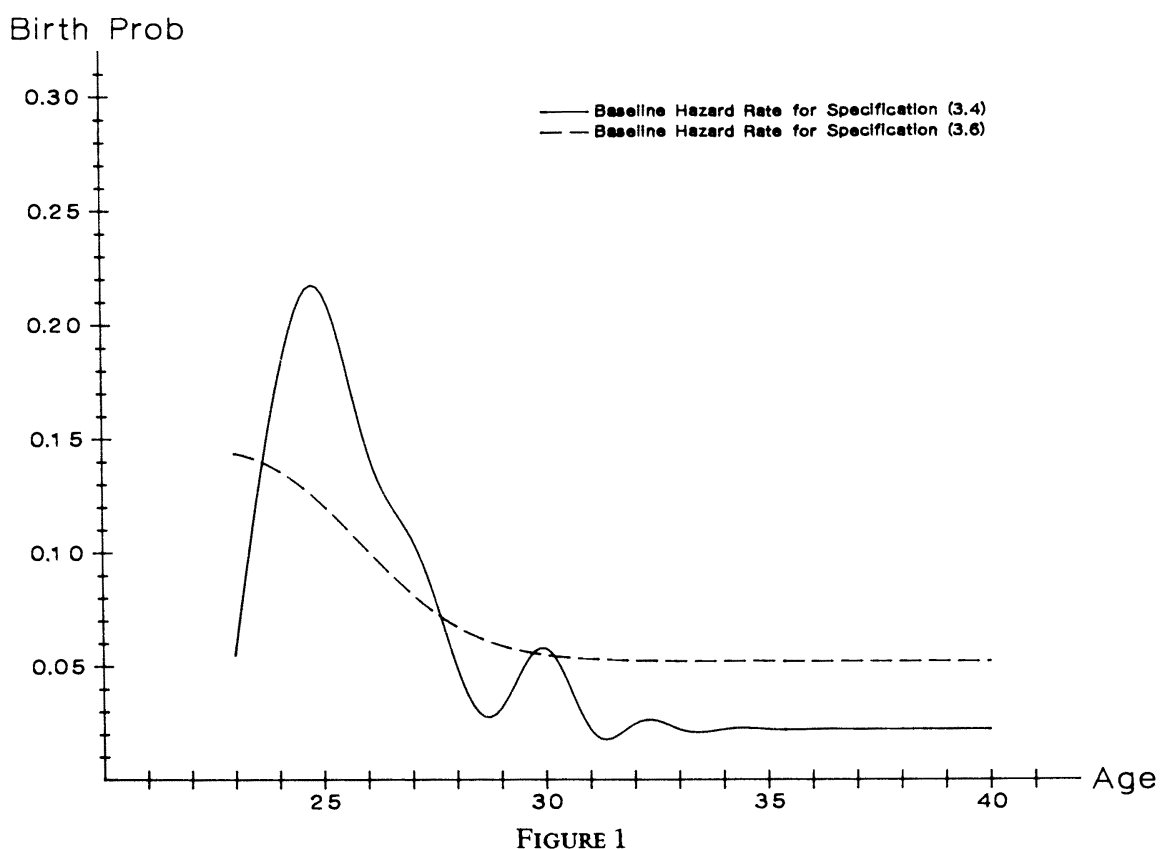

were formed using these estimates, the sample mean for the husband's educational attainment, and assumed the husband was 3 years older than his spouse.

In Figure 1 two alternative hazard rates are plotted for this representative household. The solid line was generated using the estimates for specification (3.4); the dashed line plots the estimated hazard when the effects of lagged births are constrained to be the same, i.e., specification (3.6). The initial steep increase in the plot of the solid line is mainly due to the relative increase across the implied estimates of $\tilde{\nu}_{41}, \tilde{\nu}_{42}$, and $\tilde{\nu}_{43}$ previously noted. Recall we found that the coefficients on the father's income and child care costs are, respectively, positive and negative for this specification. Since husband's income, on average, increases throughout the sample period and $c_{i t}$ is found to diminish as children age, these factors, acting by themselves, would lead to a rising hazard. However, they are more than offset by the aging of the mother and the declining values of the $\tilde{\nu}_{4 k}$ in $k$ associated with older children. Thus the resulting hazard falls over time.

The hazard rate for the rejected specification (3.6) shows a much smoother duration pattern because of the more limited way in which lagged births affect it. The counterintuitive signs on the coefficient estimates obtained can also be explained with reference to the birth hazard. When specification (3.6) is imposed on the data (i.e., when the effect of existing children, net of maternal time care costs, are constrained to not vary with the age of children), the minimizing algorithm finds other ways to achieve a downward trend in the hazard in order to accord with the data. In the sample, the additional influences of offspring older than 3 are positively correlated with the father's income and negatively correlated 


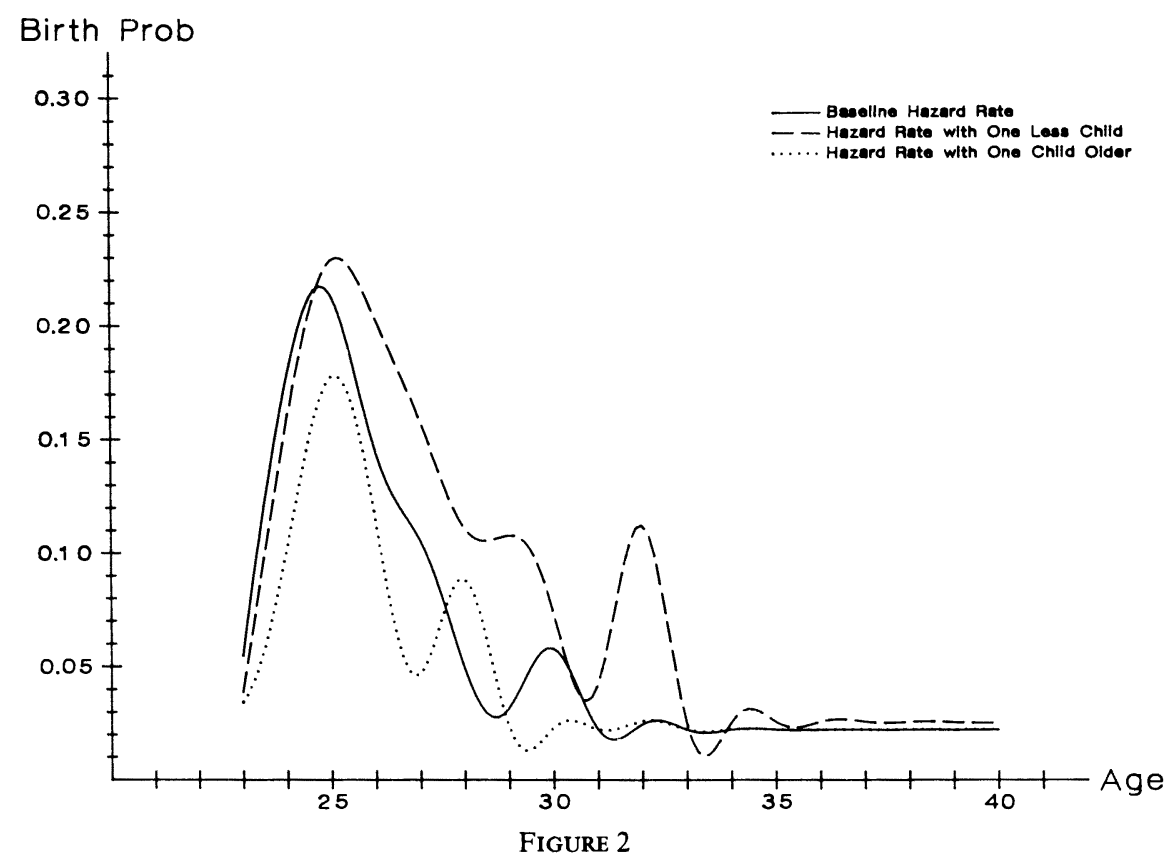

with child care costs. Hence by imposing specification (3.6), the effects of these latter two variables end up proxying for the age-varying lagged birth effects as well as their own impacts. Our estimates and the plot in Figure 1 suggest this former effect dominates the shape of the hazard and provide an explanation as to why the signs on $y_{i t}$ and $c_{i t}$ are opposite of those found for (3.4). As discussed above, the hypothesis tests show such smoothing is unwarranted. Regardless of how one interprets our coefficients on lagged births, the evidence indicates these variables should enter the hazard in a flexible manner.

Figure 2 illustrates the effects of changing the number and age distribution of existing offspring on the birth hazard using estimates for specification (3.4). The solid line, which serves as a baseline, is the same as in Figure 1. The dashed line plots the hazard given that the household had one less child (i.e., the first birth occurred when the mother was 22); otherwise the factors affecting the hazard rate are identical to the baseline case. Comparing the latter hazard plot with the baseline case, we see that fewer children increase the hazard rate of another birth at virtually every duration. The dotted line in Figure 2 plots the hazard in the situation where there were two previous births but the first occurred when the mother was 18 rather than 20 while the second occurred, as in the baseline, at age 22. Comparing this situation with the baseline, we see that having older children tends to depress the hazard rate at shorter durations, while the two rates are approximately equal for longer durations. (It is actually the case that the dotted line lies above the solid line after age 34.) The effect of varying the age 


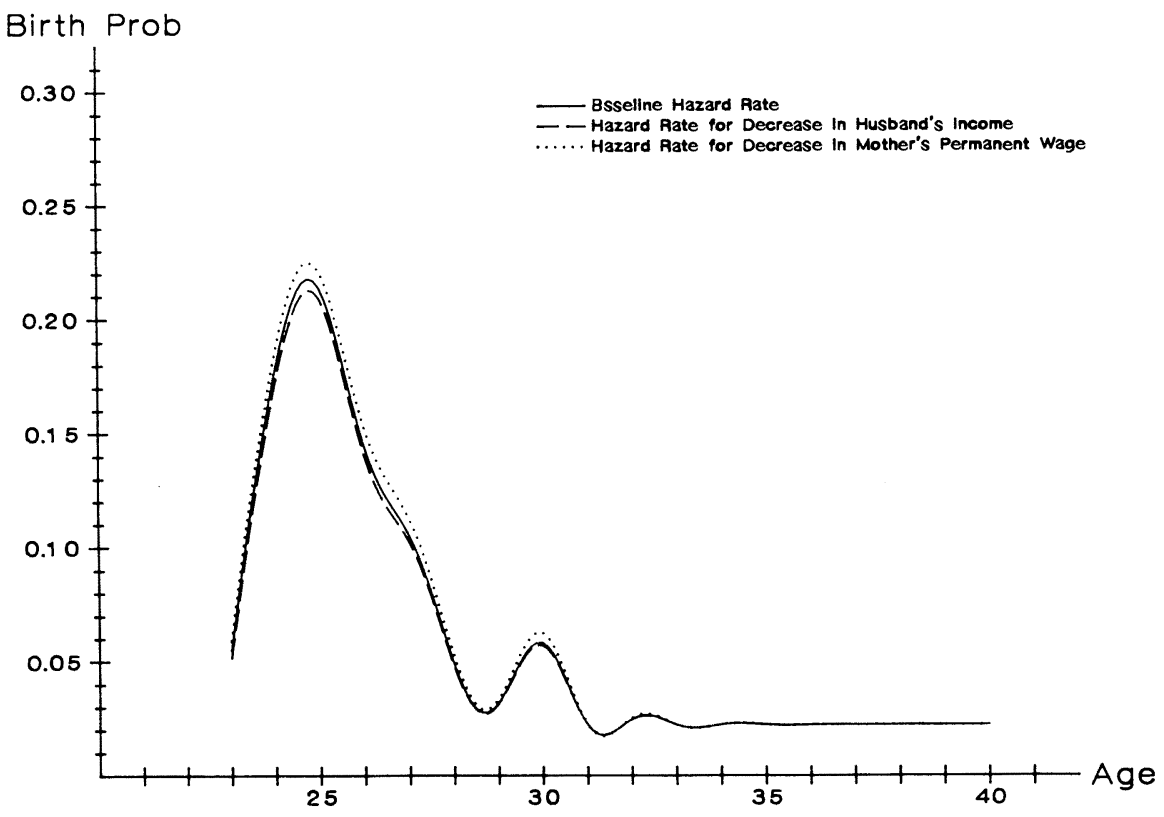

FIGURE 3

distribution of existing children on birth probabilities reflects the net effects of changes in the maternal child care inputs and variation in the effects of children of different ages. These plots indicate that the impact of older children on the desire for an additional birth predominate, especially at shorter durations, and might indicate that older children substitute for greater numbers in providing utility to parents.

Finally, Figure 3 illustrates the effects of changes in the market variables on the birth hazard. The solid line is identical to those in the previous figures. The dotted line imposes a one standard deviation downward shift in the mother's wage profile, i.e., $\kappa_{2}$ is reduced by 1.52 units. The dashed line is obtained by reducing the husband's income by a standard deviation (which is 5.23 in our sample) in the year his spouse is 22. Otherwise the specifications are identical to the baseline. These plots reflect the sign patterns already noted for changes in the mother's wage and the husband's income; they also reflect the fact that the magnitudes of these effects are relatively small.

Program in Quantitative Economic Analysis /NORC, University of Chicago, Chicago, IL 60637, U.S.A.

and

Graduate School of Industrial Administration, Carnegie-Mellon University, Pittsburgh, PA 15213, U.S.A. 


\section{APPENDIX}

This Appendix describes a limited Monte Carlo study undertaken to investigate the properties of estimators in which fixed effects are treated as parameters and estimated jointly with the other parameters in a nonlinear model.

We generated 25 samples for each of two sample sizes, $N=50$ and $N=200$ households. Each household consisted of a couple who were married when the woman was 18 and the husband was 21 and had at least one birth. We randomly generated the mother's age at which the first birth occurred. (We assumed one fifth of the couples had their first birth in the $r$ th year of marriage, where $r=1, \ldots, 5$.) Subsequent births and the woman's labor supply and market wage rates were then generated by equations (2.1), (2.2), (2.3), (2.8), and (2.9). In these equations, we assumed that: $\psi_{k}=\psi_{1}, \gamma_{k}=\gamma_{1} \delta^{k-1}$, for all $k, \tilde{\nu}_{4 k}$ varied for $k=1, \ldots, 6$ and $\tilde{\nu}_{4 k}=\tilde{\nu}_{47}$, for $k \geqslant 7$.

We chose true parameter values based on the parameter estimates obtained in our empirical work. In the child care equation, we set $\gamma_{1}=0.600$ and $\delta=0.88$. In the mother's labor supply equation, we set $\eta_{1}=-0.03, \eta_{2}=1.4, \eta_{3}=-0.9$, and $\eta_{4} \psi_{1}=0.01$, while for the mother's wage process, we used $\alpha_{1}=0.10$ and $\alpha_{2}=0.001$. For the fertility behavior, we set $\tilde{\nu}_{0}=2.0, \tilde{\nu}_{1}=0.015, \tilde{\nu}_{2}=-5.0, \tilde{\nu}_{3} \psi_{1}+\tilde{\nu}_{41}$ $=1.2, \tilde{\nu}_{3} \psi_{1}+\tilde{\nu}_{42}=2.4, \tilde{\nu}_{3} \psi_{1}+\tilde{\nu}_{43}=3.0, \tilde{\nu}_{3} \psi_{1}+\tilde{\nu}_{44}=2.4, \tilde{\nu}_{3} \psi_{1}+\tilde{\nu}_{45}=1.2, \tilde{\nu}_{3} \psi_{1}+\tilde{\nu}_{46}=0.6, \tilde{\nu}_{3} \psi_{1}+$ $\tilde{\nu}_{47}=0.5, \tilde{\nu}_{5}=-0.1, \tilde{v}_{6}=-0.05, \tilde{\nu}_{7}=-0.01, \tilde{\nu}_{8}=-0.25$, and $\tilde{\nu}_{9}=-0.15$. The conception probabilities used were $p=0.05$ and $\bar{p}=0.30$. The transitory components, $u_{1 t}^{*}$ and $u_{2 t}^{*}$, were drawn from a bivariate normal distribution with zero means and covariance matrix $\Omega$, with elements $\sqrt{\omega_{11}}=0.7$, $\omega_{12}=-0.3$, and $\sqrt{\omega_{22}}=1.6$. For each household, the elements $\kappa_{1 i}$ and $\kappa_{2 i}$ were each drawn from independent normal distributions with means -2.0 and 0.6 and standard deviations 2.0 and 1.5, respectively. The husband's income was generated using the following equation:

$$
y_{i t}=-0.15+0.87 y_{i t-1}+0.1 \mathrm{AGE}_{i t}-0.0015 \mathrm{AGE}_{i t}^{2}+v_{i t},
$$

where $\mathrm{AGE}_{i t}$ is the husband's age at $t_{i}, v_{i t}$ is drawn from an independently distributed uniform distribution with support $[-0.5,0.5]$, and the initial husband's income is drawn from a uniform distribution with support $[5.5,6.5]$.

From each household history, we randomly selected 10 consecutive time periods for inclusion in the sample. (One tenth of the households were sampled for 10 periods starting when the wife was 21 years old, a second tenth were sampled for 10 periods when the wife was 22, and so on.) To determine how well our strategy of estimating fixed effects jointly with other parameters did at recovering the true parameter values, we estimated the "reduced form" labor supply and labor force participation equations given in (2.10). That is,

$$
h_{i t}=\eta_{1} y_{i t}+\eta_{2} \alpha_{1} t_{i}+\eta_{2} \alpha_{2} t_{i}^{2}+\sum_{k=1}^{K}\left(\eta_{3} \gamma_{1} \delta^{k-1}+\eta_{4} \psi_{1}\right) b_{i, t-k}+\kappa_{1 i}^{*}+\varepsilon_{1 i t},
$$

where $\kappa_{1 i}^{*}=\kappa_{1 i}+\eta_{2} \kappa_{2 i}+\eta_{2} \alpha_{0}$. This equation is estimated using ML methods for data sets generated with the above set of true parameters.

The results are reported in Table A.I. It shows the true parameter values, the means (across 25 samples) of the parameter estimates obtained when the true fixed effects are included as variables in the Tobit estimation, and the means of the parameter estimates obtained when we estimate these parameters and a fixed effect for each household in the sample. For each set of estimates, we report: the means of the estimates (in the first row); the sample standard deviation of these mean parameter estimates (in the second row); and the $t$ statistic for the test that the mean estimate is significantly different from the true parameter value (in the third row).

For $N=50$, we find that both the parameter estimates obtained using the true fixed effects as regressors and the parameter estimates obtained when the fixed effects themselves were estimated, exhibit some small sample bias. In terms of percentage deviations of the means from the true values, the first group of estimates tends to be less biased than the second group, although the bias is greater in absolute value for the former estimates of $\eta_{1}$ than the latter. Moreover, based on the $t$ statistics, the means of the estimates obtained when the fixed effects were estimated actually tend to be closer to the true parameters than those in which the true fixed effects were included as regressors.

The small sample bias in both sets of estimates is reduced for almost every parameter when the number of households is increased from 50 to 200. This finding is as expected for the case in which the actual fixed effects are used as regressors, but it suggests that increasing the number of households may reduce bias in the parameter estimates even when the fixed effects are estimated. Note that the bias falls more for the former estimators than the latter; the percentage deviations of the mean 
TABLE A.I

Mean Parameter Estimates from Monte Carlo Study of Fixed Effect Estimators for the FeMale Labor SUPPly EQUation

\begin{tabular}{|c|c|c|c|c|c|c|c|}
\hline$\eta_{1}$ & $\eta_{2} \alpha_{1}$ & $\eta_{2} \alpha_{2}$ & $\eta_{3} \gamma_{1}$ & $\delta$ & $\eta_{4} \psi_{1}$ & $\sqrt{\omega_{11}}$ & Coef. on $\kappa_{11}^{*}$ \\
\hline \multicolumn{8}{|c|}{ True Parameters: } \\
\hline & 0.042 & -0.00042 & -0.162 & 0.880 & 0.003 & 0.770 & 1.000 \\
\hline \multicolumn{8}{|c|}{$N=50$ and $T=10$} \\
\hline \multicolumn{8}{|c|}{ Mean Estimates Obtained Using True Fixed Effects as Regressors: } \\
\hline $\begin{array}{c}-0.0028 \\
(0.0096) \\
2.879\end{array}$ & $\begin{array}{c}0.039 \\
(0.017) \\
-0.862\end{array}$ & $\begin{array}{c}-0.00034 \\
(0.00050) \\
0.726\end{array}$ & $\begin{array}{c}-0.185 \\
(0.175) \\
-0.588\end{array}$ & $\begin{array}{c}0.683 \\
(0.313) \\
-2.815\end{array}$ & $\begin{array}{c}-0.044 \\
(0.118) \\
-1.800\end{array}$ & $\begin{array}{c}0.777 \\
(0.029) \\
1.083\end{array}$ & $\begin{array}{c}0.992 \\
(0.170) \\
-0.210\end{array}$ \\
\hline \multicolumn{8}{|c|}{ Mean Estimates Obtained Estimating Fixed Effects: } \\
\hline $\begin{array}{c}-0.0037 \\
(0.0233) \\
1.127\end{array}$ & $\begin{array}{c}0.058 \\
(0.209) \\
0.378\end{array}$ & $\begin{array}{c}-0.00075 \\
(0.00348) \\
-0.474\end{array}$ & $\begin{array}{c}-0.241 \\
(0.240) \\
-1.646\end{array}$ & $\begin{array}{c}0.799 \\
(0.272) \\
-1.489\end{array}$ & $\begin{array}{c}0.078 \\
(0.230) \\
1.630\end{array}$ & $\begin{array}{c}0.736 \\
(0.030) \\
-5.686\end{array}$ & \\
\hline \multicolumn{8}{|c|}{$N=200$ and $T=10$} \\
\hline $\begin{array}{c}\text { Mean Estin } \\
-0.0082 \\
(0.0061) \\
0.620\end{array}$ & $\begin{array}{c}\text { abtes Obtain } \\
0.039 \\
(0.008) \\
-1.588\end{array}$ & $\begin{array}{c}\text { Using True } \\
-0.00034 \\
(0.00025) \\
1.540\end{array}$ & $\begin{array}{c}\text { ixed Effects } \\
-0.159 \\
(0.072) \\
-0.207\end{array}$ & $\begin{array}{c}\text { Regresso } \\
0.852 \\
(0.097) \\
-1.448\end{array}$ & $\begin{array}{c}0.003 \\
(0.053) \\
0.033\end{array}$ & $\begin{array}{c}0.791 \\
(0.016) \\
6.481\end{array}$ & $\begin{array}{c}0.999 \\
(0.069) \\
-0.073\end{array}$ \\
\hline $\begin{array}{c}\text { Mean Estin } \\
-0.0104 \\
(0.0093) \\
-0.753\end{array}$ & $\begin{array}{c}\text { ates Obtain } \\
0.051 \\
(0.080) \\
0.594\end{array}$ & $\begin{array}{c}\text { Estimating } \\
-0.00064 \\
(0.00129) \\
-0.872\end{array}$ & $\begin{array}{c}\text { xed Effects. } \\
-0.192 \\
(0.089) \\
-1.684\end{array}$ & $\begin{array}{c}0.900 \\
(0.371) \\
0.270\end{array}$ & $\begin{array}{c}0.058 \\
(0.108) \\
2.528\end{array}$ & $\begin{array}{c}0.743 \\
(0.012) \\
-11.250\end{array}$ & \\
\hline
\end{tabular}

estimates from the true parameters tend to be smaller when the true fixed effects are included as regressors than when they are estimated, with the exception of the estimates of $\delta$. Examining the associated $t$ statistics, the estimates where the fixed effects are included as regressors are, with the exception of the estimates of $\sqrt{\omega_{11}}$, within two standard deviations of the true parameters; the same is true for those where the fixed effects are estimated, except for the estimates of $\sqrt{\omega_{11}}$ and $\eta_{4} \psi_{1}$.

While this investigation is limited in scope, it indicates that there is small sample bias when estimating fixed effects jointly with the other parameters. Some of this bias is attributable to the small number of households in the sample, while the remainder is due to the short panel length. This bias apparently diminishes as just $N$ is increased. Finally, for both sample sizes, the extent of bias relative to sample variability is not substantial based on a standard $t$ test for almost every parameter estimate. These results tentatively suggest that while estimation of fixed effects in nonlinear models (such as used in our analysis) should be done with caution when the number of time periods per household is small, the guidance from asymptotic distribution theory for samples with reasonably large numbers of households may not be that bad.

\section{REFERENCES}

BECKER, G. (1965): "A Theory of the Allocation of Time," Economic Journal, 75, 496-517.

BUTZ, W., AND M. WARD (1979): “The Emergence of Countercyclical U.S. Fertility," American Economic Review, 69, 318-328.

CaIN, G. (1966): Labor Force Participation of Married Women. Chicago: University of Chicago Press.

Cogan, J. (1980): “Married Women's Labor Supply: A Comparison of Alternative Estimation Procedures," in Female Labor Supply: Theory and Evidence, ed. by J. Smith. Princeton: Princeton University Press.

David, P., AND T. Mroz (1986): "A Sequential Econometric Model of Birth-Spacing Behavior among Rural French Villagers, 1749-1789," unpublished manuscript. 
Deaton, A., And J. Muellbauer (1980): Economics and Consumer Behavior. Cambridge: Cambridge University Press.

EsPenshade, T. (1984): Investing in Children: New Estimates of Parental Expenditures. Washington, D.C.: Urban Institute Press.

Ferguson, T. (1958): "A Method of Generating Best Asymptotically Normal Estimators with Application to the Estimation of Bacterial Densities," Annals of Mathematical Statistics, 29, $1046-1062$.

GronaU, R. (1986): "The Intrafamily Allocation of Goods-How to Separate the Men from the Boys," unpublished manuscript.

Hansen, L. P. (1982): "Large Sample Properties of Generalized Methods of Moments Estimators," Econometrica, 50, 1029-1054.

HeCKMAn, J. (1974): "Shadow Prices, Market Wages and Labor Supply," Econometrica, 42, 679-694. (1981): "The Incidental Parameters Problem and the Problem of Initial Conditions in Estimating a Discrete Time-Discrete Data Stochastic Process," in Structural Analysis of Discrete Data with Econometric Applications, ed. by C. Manski and D. McFadden. Cambridge: MIT Press.

Heckman, J., AND T. MaCURDy (1980): “A Life Cycle Model of Female Labour Supply," Review of Economic Studies, 47, 47-74.

(1982): "Corrigendum on a Life Cycle Model of Female Labour Supply," Review of Economic Studies, 49, 659-660.

HeCKMAN, J., AND R. Willis (1976): "Estimation of a Stochastic Model of Reproduction: An Econometric Approach," in Household Production and Consumption, ed. by N. Terleckyj. New York: Columbia University Press.

Hill, C. R., AND F. STAFFoRd (1980): "Parental Care of Children: Time Diary Estimates of Quantity, Predictability and Variety," Journal of Human Resources, 15, 220-239.

Hotz, V. J. (1980): A Life Cycle Model of Fertility and Married Women's Labor Supply. Ph.D. Dissertation, University of Wisconsin.

Hotz, V. J., AND R. Miller (1986): “The Economics of Family Planning," unpublished manuscript.

Lazear, E., AND R. Michael (1980): “Family Size and the Distribution of Real Per Capita Income," American Economic Review, 70, 91-107.

MINCER, J. (1963): “Opportunity Costs and Income Effects," in Measurement in Economics, ed. by C. Christ, et al. Stanford, CA: Stanford University Press.

Namboodiri, N. (1972): "Some Observations on the Economics Framework for Fertility Analysis," Population Studies, 26, 185-206.

POLlaK, R., AND T. WALES (1980): "Comparison of the Quadratic Expenditure System and Translog Demand Systems with Alternative Specifications of Demographic Effects," Econometrica, 48, $595-612$.

Rosenzweig, M., and T. P. Schultz (1985): “The Demand and Supply of Births," American Economic Review, 75, 992-1015.

Schultz, T. P. (1978): "The Influence of Fertility on Labor Supply of Married Women: Simultaneous Equation Estimates," in Research in Labor Economics, Vol. 2, ed. by R. Ehrenberg. Greenwich, CT: JAI Press.

ShePs, M., AND J. Menken (1973): Mathematical Models of Conception and Birth. Chicago: University of Chicago Press.

White, H. (1982): "Maximum Likelihood Estimation of Misspecified Models," Econometrica, 50, $1-26$.

WILLIS, R. (1973): "A New Approach to the Economic Theory of Fertility Behavior," Journal of Political Economy, 81, 514-564.

Wolpin, K. (1984): "An Estimable Dynamic Stochastic Model of Fertility and Child Mortality," Journal of Political Economy, 92, 852-874. 
http://www.jstor.org

\title{
LINKED CITATIONS
}

- Page 1 of 4 -

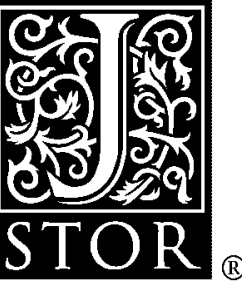

You have printed the following article:

\section{An Empirical Analysis of Life Cycle Fertility and Female Labor Supply}

V. Joseph Hotz; Robert A. Miller

Econometrica, Vol. 56, No. 1. (Jan., 1988), pp. 91-118.

Stable URL:

http://links.jstor.org/sici?sici=0012-9682\%28198801\%2956\%3A1\%3C91\%3AAEAOLC\%3E2.0.CO\%3B2-O

This article references the following linked citations. If you are trying to access articles from an off-campus location, you may be required to first logon via your library web site to access JSTOR. Please visit your library's website or contact a librarian to learn about options for remote access to JSTOR.

\section{[Footnotes]}

\author{
${ }^{4}$ Family Size and the Distribution of Real Per Capita Income \\ Edward P. Lazear; Robert T. Michael \\ The American Economic Review, Vol. 70, No. 1. (Mar., 1980), pp. 91-107. \\ Stable URL: \\ http://links.jstor.org/sici?sici=0002-8282\%28198003\%2970\%3A1\%3C91\%3AFSATDO\%3E2.0.CO\%3B2-9

\section{${ }^{8}$ Maximum Likelihood Estimation of Misspecified Models} \\ Halbert White \\ Econometrica, Vol. 50, No. 1. (Jan., 1982), pp. 1-25. \\ Stable URL: \\ http://links.jstor.org/sici?sici=0012-9682\%28198201\%2950\%3A1\%3C1\%3AMLEOMM\%3E2.0.CO\%3B2-C
}

\footnotetext{
${ }^{9}$ A Life Cycle Model of Female Labour Supply

James J. Heckman; Thomas E. Macurdy

The Review of Economic Studies, Vol. 47, No. 1, Econometrics Issue. (Jan., 1980), pp. 47-74.

Stable URL:

http://links.jstor.org/sici?sici=0034-6527\%28198001\%2947\%3A1\%3C47\%3AALCMOF\%3E2.0.CO\%3B2-\%23
}

\footnotetext{
${ }^{10}$ A Life Cycle Model of Female Labour Supply

James J. Heckman; Thomas E. Macurdy

The Review of Economic Studies, Vol. 47, No. 1, Econometrics Issue. (Jan., 1980), pp. 47-74.

Stable URL:

http://links.jstor.org/sici?sici=0034-6527\%28198001\%2947\%3A1\%3C47\%3AALCMOF\%3E2.0.CO\%3B2-\%23
}

NOTE: The reference numbering from the original has been maintained in this citation list. 
http://www.jstor.org

\title{
LINKED CITATIONS
}

- Page 2 of 4 -

\author{
${ }^{12}$ Large Sample Properties of Generalized Method of Moments Estimators \\ Lars Peter Hansen \\ Econometrica, Vol. 50, No. 4. (Jul., 1982), pp. 1029-1054. \\ Stable URL: \\ http://links.jstor.org/sici?sici=0012-9682\%28198207\%2950\%3A4\%3C1029\%3ALSPOGM\%3E2.0.CO\%3B2-O \\ ${ }^{14}$ Corrigendum on A Life Cycle Model of Female Labour Supply \\ James J. Heckman; Thomas MaCurdy \\ The Review of Economic Studies, Vol. 49, No. 4. (Oct., 1982), pp. 659-660. \\ Stable URL: \\ http://links.jstor.org/sici?sici=0034-6527\%28198210\%2949\%3A4\%3C659\%3ACOALCM\%3E2.0.CO\%3B2-F
}

\section{References}

\author{
A Theory of the Allocation of Time \\ Gary S. Becker \\ The Economic Journal, Vol. 75, No. 299. (Sep., 1965), pp. 493-517. \\ Stable URL: \\ http://links.jstor.org/sici?sici=0013-0133\%28196509\%2975\%3A299\%3C493\%3AATOTAO\%3E2.0.CO\%3B2-N

\section{The Emergence of Countercyclical U.S. Fertility} \\ William P. Butz; Michael P. Ward \\ The American Economic Review, Vol. 69, No. 3. (Jun., 1979), pp. 318-328. \\ Stable URL: \\ http://links.jstor.org/sici?sici=0002-8282\%28197906\%2969\%3A3\%3C318\%3ATEOCUF\%3E2.0.CO\%3B2-B
}

\author{
A Method of Generating Best Asymptotically Normal Estimates with Application to the \\ Estimation of Bacterial Densities \\ Thomas S. Ferguson \\ The Annals of Mathematical Statistics, Vol. 29, No. 4. (Dec., 1958), pp. 1046-1062. \\ Stable URL: \\ http://links.jstor.org/sici?sici=0003-4851\%28195812\%2929\%3A4\%3C1046\%3AAMOGBA\%3E2.0.CO\%3B2-U
}

NOTE: The reference numbering from the original has been maintained in this citation list. 
http://www.jstor.org

\section{LINKED CITATIONS}

- Page 3 of 4 -

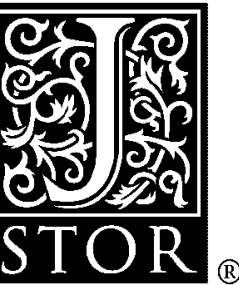

\section{Large Sample Properties of Generalized Method of Moments Estimators}

Lars Peter Hansen

Econometrica, Vol. 50, No. 4. (Jul., 1982), pp. 1029-1054.

Stable URL:

http://links.jstor.org/sici?sici=0012-9682\%28198207\%2950\%3A4\%3C1029\%3ALSPOGM\%3E2.0.CO\%3B2-O

\section{Shadow Prices, Market Wages, and Labor Supply}

James Heckman

Econometrica, Vol. 42, No. 4. (Jul., 1974), pp. 679-694.

Stable URL:

http://links.jstor.org/sici?sici=0012-9682\%28197407\%2942\%3A4\%3C679\%3ASPMWAL\%3E2.0.CO\%3B2-S

\section{A Life Cycle Model of Female Labour Supply}

James J. Heckman; Thomas E. Macurdy

The Review of Economic Studies, Vol. 47, No. 1, Econometrics Issue. (Jan., 1980), pp. 47-74.

Stable URL:

http://links.jstor.org/sici?sici=0034-6527\%28198001\%2947\%3A1\%3C47\%3AALCMOF\%3E2.0.CO\%3B2-\%23

\section{Corrigendum on A Life Cycle Model of Female Labour Supply}

James J. Heckman; Thomas MaCurdy

The Review of Economic Studies, Vol. 49, No. 4. (Oct., 1982), pp. 659-660.

Stable URL:

http://links.jstor.org/sici?sici=0034-6527\%28198210\%2949\%3A4\%3C659\%3ACOALCM\%3E2.0.CO\%3B2-F

Parental Care of Children: Time Diary Estimates of Quantity, Predictability, and Variety C. Russell Hill; Frank P. Stafford

The Journal of Human Resources, Vol. 15, No. 2. (Spring, 1980), pp. 219-239.

Stable URL:

http://links.jstor.org/sici?sici=0022-166X\%28198021\%2915\%3A2\%3C219\%3APCOCTD\%3E2.0.CO\%3B2-3

\section{Family Size and the Distribution of Real Per Capita Income}

Edward P. Lazear; Robert T. Michael

The American Economic Review, Vol. 70, No. 1. (Mar., 1980), pp. 91-107.

Stable URL:

http://links.jstor.org/sici?sici=0002-8282\%28198003\%2970\%3A1\%3C91\%3AFSATDO\%3E2.0.CO\%3B2-9

NOTE: The reference numbering from the original has been maintained in this citation list. 
http://www.jstor.org

\title{
LINKED CITATIONS \\ - Page 4 of 4 -
}

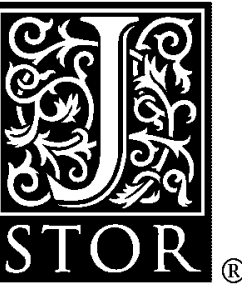

Some Observations on the Economic Framework for Fertility Analysis

N. Krishnan Namboodiri

Population Studies, Vol. 26, No. 2. (Jul., 1972), pp. 185-206.

Stable URL:

http://links.jstor.org/sici?sici=0032-4728\%28197207\%2926\%3A2\%3C185\%3ASOOTEF\%3E2.0.CO\%3B2-I

Comparison of the Quadratic Expenditure System and Translog Demand Systems with Alternative Specifications of Demographic Effects

Robert A. Pollak; Terence J. Wales

Econometrica, Vol. 48, No. 3. (Apr., 1980), pp. 595-612.

Stable URL:

http://links.jstor.org/sici?sici=0012-9682\%28198004\%2948\%3A3\%3C595\%3ACOTOES\%3E2.0.CO\%3B2-A

The Demand for and Supply of Births: Fertility and its Life Cycle Consequences

Mark R. Rosenzweig; T. Paul Schultz

The American Economic Review, Vol. 75, No. 5. (Dec., 1985), pp. 992-1015.

Stable URL:

http://links.jstor.org/sici?sici=0002-8282\%28198512\%2975\%3A5\%3C992\%3ATDFASO \%3E2.0.CO\%3B2-1

\section{Maximum Likelihood Estimation of Misspecified Models}

Halbert White

Econometrica, Vol. 50, No. 1. (Jan., 1982), pp. 1-25.

Stable URL:

http://links.jstor.org/sici?sici=0012-9682\%28198201\%2950\%3A1\%3C1\%3AMLEOMM\%3E2.0.CO\%3B2-C

\section{A New Approach to the Economic Theory of Fertility Behavior}

Robert J. Willis

The Journal of Political Economy, Vol. 81, No. 2, Part 2: New Economic Approaches to Fertility. (Mar. - Apr., 1973), pp. S14-S64.

Stable URL:

http://links.jstor.org/sici?sici=0022-3808\%28197303\%2F04\%2981\%3A2\%3CS14\%3AANATTE\%3E2.0.CO\%3B2-K

\author{
An Estimable Dynamic Stochastic Model of Fertility and Child Mortality \\ Kenneth I. Wolpin \\ The Journal of Political Economy, Vol. 92, No. 5. (Oct., 1984), pp. 852-874. \\ Stable URL: \\ http://links.jstor.org/sici?sici=0022-3808\%28198410\%2992\%3A5\%3C852\%3AAEDSMO\%3E2.0.CO\%3B2-F
}

NOTE: The reference numbering from the original has been maintained in this citation list. 